\title{
WILEY-VCH
}

\section{How Humidity and Light Exposure Change the Photophysics of Metal Halide Perovskite Solar Cells}

Esma Ugur, * Erkki Alarousu, Jafar I. Khan, Aleš Vlk, Erkan Aydin, Michele De Bastiani, Ahmed H. Balawi, Sandra P. Gonzalez-Lopez, Martin Ledinský, Stefaan De Wolf, and Frédéric Laquai*

E. Ugur, Dr. E. Alarousu, Dr. J. I. Khan, Dr. E. Aydin, Dr. M. De Bastiani, Dr. A. H. Balawi, S. P. Gonzalez-Lopez, Prof. S. De Wolf, Prof. F. Laquai

King Abdullah University of Science and Technology (KAUST), KAUST Solar Center (KSC), Physical Sciences and Engineering Division (PSE), Material Science and Engineering Program (MSE), Thuwal, 23955-6900, Saudi Arabia

E-mail: esma.ugur@kaust.edu.sa; frederic.laquai@kaust.edu.sa

\section{Aleš Vlk, Dr. M. Ledinský}

Laboratory of Nanostructures and Nanomaterials, Institute of Physics, Academy of Sciences of the Czech Republic, v. v. i., Cukrovarnická 10, 16200 Prague, Czech Republic

Keywords: metal-halide perovskites, perovskite solar cells, perovskite photophysics, photodegradation

\section{ABSTRACT}

Metal halide perovskites exhibit outstanding optical and electronic properties, but are very sensitive to humidity and light-soaking. In this work, the photophysics of perovskites that have been exposed to such conditions are studied and, in this context, the impact of excess lead iodide $\left(\mathrm{PbI}_{2}\right)$ is revealed. For exposed samples, the formation of sub-bandgap states and increased trap-assisted recombination is observed, using highly-sensitive absorption and timeresolved photoluminescence (TRPL) measurements, respectively. It appears that such exposure primarily affects the perovskite surface. Consequently, on $n-i-p$ device level, the spiro-OMeTAD/perovskite interface should be more rapidly affected than its buried electroncollecting interface. Moreover, both stoichiometric and non-stoichiometric $\mathrm{MAPbI}_{3}$-based solar cells show reduced device performance mainly due to voltage losses. Overall, this study brings forward key points to consider in engineering perovskite solar cells with improved performance and material stability. 


\section{WILEY-VCH}

\section{Introduction}

Perovskite solar cells (PSCs) have gained widespread attention in the photovoltaic (PV) community due to their excellent optical and electronic properties, in addition to their ease of fabrication at an affordable cost. ${ }^{[1,2]}$ Thanks to these properties, together with significant device engineering efforts, the power conversion efficiency (PCE) of PSCs has exceeded the $25 \%$ barrier recently. ${ }^{[3]}$ However, the photophysical properties of perovskites, and therefore the performance of PSCs, and their long-term stability are susceptible to extrinsic effects such as humidity, light-soaking, and thermal stress. ${ }^{[4,5,6-8]}$ Of the aforementioned extrinsic parameters, the precise effects of humidity and light exposure are still under debate; some studies claim both to be beneficial, while others report them to be detrimental. For instance, Pathak et al. reported that annealing perovskite films in humid air resulted in improved crystallinity and larger perovskite grain domains, yielding a higher photoluminescence quantum efficiency (PLQE). ${ }^{[9]}$ Eperon et al. showed that exposure to humidity either in the precursor solution or from the atmosphere during film formation results in significantly improved open-circuit voltage $\left(V_{\mathrm{OC}}\right)$ due to partial solvation of the methylammonium $\left(\mathrm{MA}^{+}\right)$ and "self-healing" of the perovskite lattice. ${ }^{[10]}$ On the contrary, Yang et al. reported that humidity accelerates the device degradation by the formation of a hydrated intermediate containing isolated $\left(\mathrm{PbI}_{6}\right)^{4-}$ octahedra. ${ }^{[11]}$ Furthermore, Christians et al. observed via ultrafast transient spectroscopy that the reaction with water molecules at the surface of the films creates shallow trap states. ${ }^{[12]}$ Overall, a consensus of the effect of humidity on the performance of PSCs has yet to be reached.

To understand the interaction of oxygen with metal halide perovskites, Aristidou et al. performed ab initio simulations and demonstrated photoinduced superoxide $\left(\mathrm{O}_{2}{ }^{-}\right)$formation in $\mathrm{MAPbI}_{3}$ films. ${ }^{[7]}$ They found that the formation of this highly-diffusive oxygen species is mainly facilitated by iodide vacancies $\left(\mathrm{V}_{\mathrm{I}}\right)$ in the perovskite film, which reduces stability, 


\section{WILEY-VCH}

especially in the case of smaller perovskite crystallites. Furthermore, Brenes et al. reported that molecular oxygen $\left(\mathrm{O}_{2}\right)$ adsorbed on the surface of the perovskite after photoexcitation can act as electron scavenger and form $\mathrm{O}_{2}^{-}$, which enhances the photoluminescence (PL) yield of the perovskite by passivating sub-bandgap electron trap states associated with $\mathrm{V}_{\mathrm{I} .}{ }^{[6]}$ Meggiolaro et al. studied the interaction between $\mathrm{O}_{2}$ and perovskite and found a reversible PLQY enhancement upon exposure to $\mathrm{O}_{2}$ due to deep trap passivation effect of oxidized interstitial iodine. ${ }^{[13]}$ Furthermore, He et al. recently showed that $\mathrm{O}_{2}$ has negligible influence on the perovskite stability, while the formation of superoxide and peroxide accelerates the degradation due to $\mathrm{Pb}-\mathrm{I}$ bond cleavage. ${ }^{[8]}$ To validate the combined effect of humidity and oxygen, Brenes et al. exposed perovskite films to ambient air under continuous illumination by $532 \mathrm{~nm}$ laser light. They found that $\mathrm{MAPbI}_{3}$ films show a longer PL lifetime, suggesting passivation of surface defects. ${ }^{[14]}$ In addition, they showed that these changes are reversible on a timescale of hours when samples were kept in the dark. However, from device perspective, considering the significant effort of the PSC community to make solar cells robust against humidity, complementary characterization techniques, including structural and optoelectronic analysis, are imperative to reveal the consequences of the synergistic effects of humidity and oxygen.

Hence, we investigated the excited-state dynamics of prototypic lead halide perovskite $\left(\mathrm{MAPbI}_{3}\right)$ films used in state-of-the-art PSC devices after exposure to ambient conditions (RH $=45-55 \%)$ under 1-sun ( $\left.\mathrm{AM} 1.5 \mathrm{G}, 100 \mathrm{~mW} \mathrm{~cm}^{-2}\right)$ illumination, which mimics the irradiation under device operation conditions. Henceforth, when referring to exposed samples, they are labelled with the prefix ' $\mathrm{D}-$ '. Furthermore, we studied $\mathrm{MAPbI}_{3}$ films containing excess $\mathrm{PbI}_{2}$ and reveal the photophysical changes that govern device performance of non-stoichiometric $\mathrm{MAPbI}_{3}$. More precisely, we correlate device performance with photophysical and structural changes of the perovskite after exposure to humid air under continuous illumination. Overall, 


\section{WILEY-VCH}

we demonstrate that degradation of $\mathrm{MAPbI}_{3}$ films starts at the grain boundaries and smaller grains, independent of excess $\mathrm{PbI}_{2}$. Finally, we demonstrate that the open-circuit voltage deficit $\left(\mathrm{W}_{\mathrm{OC}}\right)$ is increased in devices, while PL lifetimes are reduced due to increased trapassisted nonradiative recombination.

\section{Results and Discussion}

First, to evaluate the change in device performance after exposing the perovskite layer to humid air under constant illumination, we fabricated reference PSCs using the $n-i-p$ device architecture; device layout and cross-sectional SEM are shown in Figure 1a, d. We investigated two types of $\mathrm{MAPbI}_{3}$ : stoichiometric, that is $\mathrm{MAPbI}_{3}$, and $\mathrm{MAPbI}_{3}$ with excess $\mathrm{PbI}_{2}$. We controlled the crystallization process using the two-step interdiffusion method with 2-methoxyethanol as additive as reported earlier by us. ${ }^{[15]}$ This method assists in controlling grain growth and excess $\mathrm{PbI}_{2}$ content. The excess of $\mathrm{PbI}_{2}$ was varied by changing the annealing temperature from 105 to $135{ }^{\circ} \mathrm{C}$ (Figure 4) without changing the conversion dynamics to avoid creating non-converted $\mathrm{PbI}_{2}$, as reported previously ${ }^{[15-17]}$ (see Experimental Section).

The $\mathrm{MAPbI}_{3}$ solar cells showed $18.73 \%$ PCE with negligible hysteresis (Figure 1b), $1136 \mathrm{mV}$ $V_{\mathrm{OC}}$, and $22.64 \mathrm{~mA} \mathrm{~cm}^{-2}$ short-circuit current density $\left(J_{\mathrm{SC}}\right)$. We note that these PCE values are close to the state-of-the-art for $\mathrm{MAPbI}_{3}$-based PSCs. We found that the performance of $\mathrm{MAPbI}_{3}$ devices slightly decreased to $18.17 \%$ (Figure 1c, Figure S7) after excess $\mathrm{PbI}_{2}$ formation, mainly due to a $\mathrm{V}_{\mathrm{OC}}$ decrease to $1109 \mathrm{mV}$ without a significant change in $\mathrm{J}_{\mathrm{SC}}$ and fill factor $(F F)$ as shown in Figure $1 \mathrm{~b}, \mathrm{c}$ and e. Integrated current density values $(\sim 21.3 \mathrm{~mA}$ $\mathrm{cm}^{-2}$ ) derived from external quantum efficiency (EQE) spectra are also in line with the current density-voltage $(J-V)$ characteristics of these devices (Figure 1e). Furthermore, we performed stabilized power output measurements to test the PCE evolution over time (Figure 1f). Both 


\section{WILEY-VCH}

MAPbI 3 and $\mathrm{MAPbI}_{3}$ with excess $\mathrm{PbI}_{2}$ devices showed stable current responses and constant PCEs, without any evidence of degradation.

a

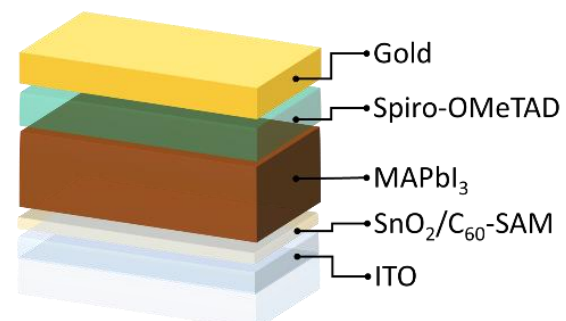

d

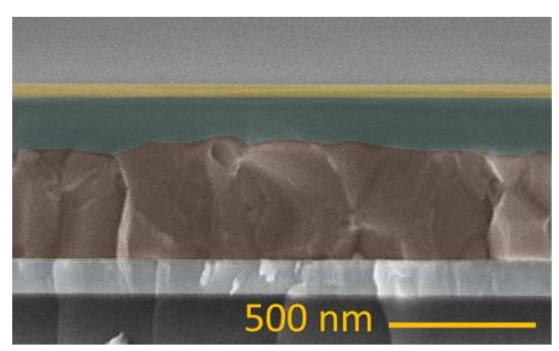

b

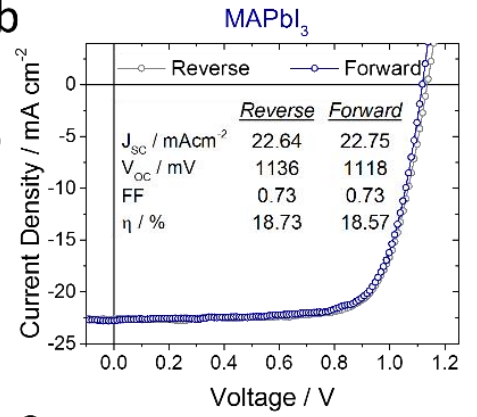

e

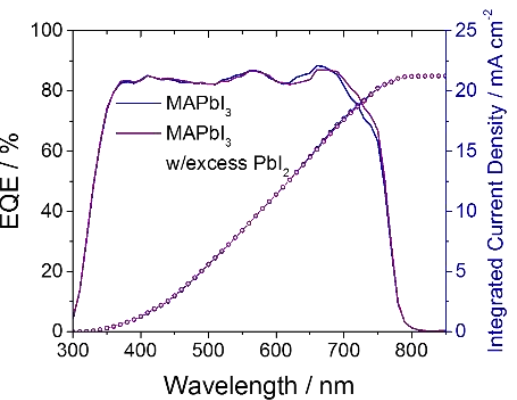

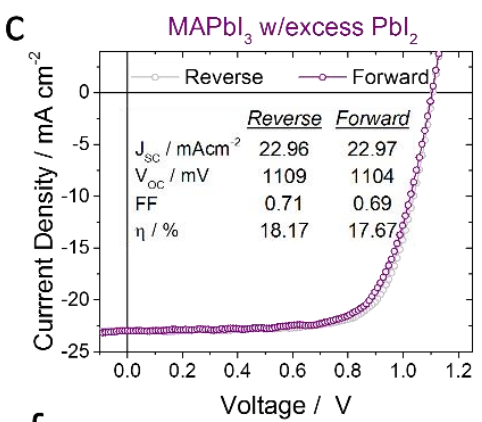

$f$

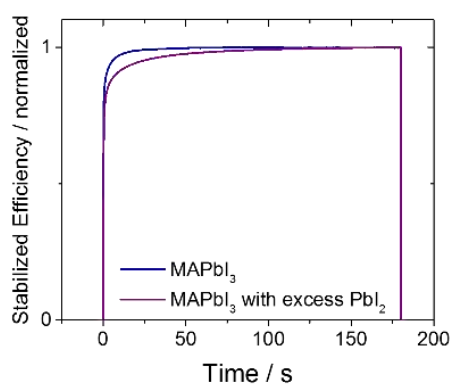

Figure 1. a) Schematic of $n-i-p$ perovskite photovoltaic device used in this study, b) and c) $J-V$ characteristics of best working $\mathrm{MAPbI}_{3}$ solar cells without excess $\mathrm{PbI}_{2}$ and with excess $\mathrm{PbI}_{2}$, respectively, d) Cross-sectional SEM image of $\mathrm{MAPbI}_{3}$ device without excess $\mathrm{PbI}_{2}$ (Scale bar: $500 \mathrm{~nm}$ ), e) EQE spectra and f) stabilized efficiency of the $\mathrm{MAPbI}_{3}$ solar cells shown in $b$ and $\mathrm{c}$.

To evaluate the optical properties of perovskite films before and after the degradation by exposure of the perovskite films to humid air with $\mathrm{RH}=45-55 \%$ under 1-sun illumination for 60 min, steady-state ultraviolet-visible (UV-vis) absorption measurements were performed

(Figure 2a-b, Figure S1). While the absorptance and the bandgap had not changed after degradation, we observed a prominent tail in the absorption spectrum below the band-edge of the perovskite films, as shown in Figure 2a. The reflectance spectra presented in Figure 2b demonstrate a significant red-shift of $\mathrm{MAPbI}_{3}$ absorption with excess $\mathrm{PbI}_{2}$, which is in line with the observed shift in the EQE spectra (700 to $750 \mathrm{~nm}$ ) of these samples (in Figure 1e). Contrarily, the degradation process left the reflectance of the samples virtually unaltered, implying similar absorption properties regardless of the adsorbed molecules. Furthermore, we 


\section{WILEY-VCH}

performed photothermal deflection spectroscopy (PDS) to reveal the absorption of subbandgap features in the perovskite films, as shown in Figure 2c. Here, we observed an additional sub-bandgap absorption for the samples exposed to humid air under illumination, consistent with the tail at the band-edge observed by steady-state UV-vis absorptance spectra. Furthermore, to confirm the presence of sub-bandgap absorption in degraded samples, PDS measurements were conducted, scanning from low energy to high photon energy and vice versa (Figure S2), which excludes that the absorption signal in the sub-bandgap region is an artifact induced by the scan direction. In fact, the sub-bandgap absorption is clearly induced by the synergetic effect of air exposure and continues illumination, as confirmed by reference measurements on films kept for 48 hours in humid air but in the dark, which did not lead to any sub-bandgap features (Figure S2e-f). The origin of the sub-bandgap absorption is indicative of secondary phases or substitutional atoms created by degradation, activated under continuous illumination. ${ }^{[18]}$

a

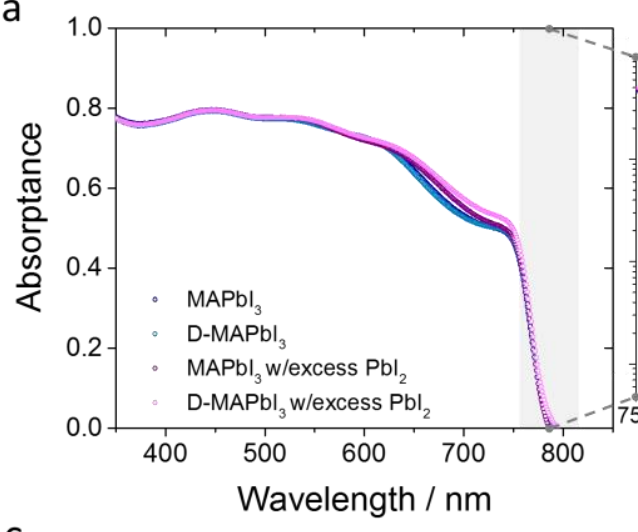

C

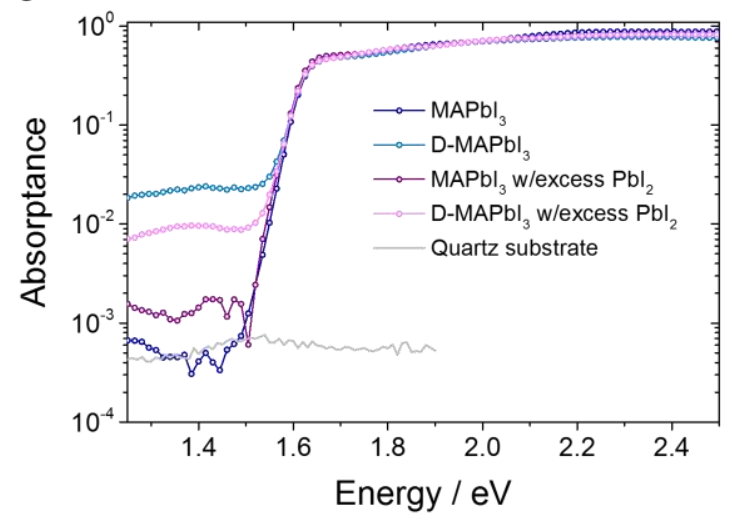

b

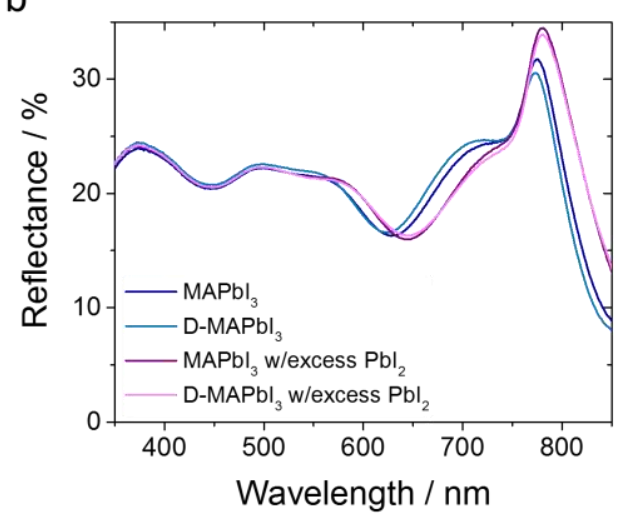

d

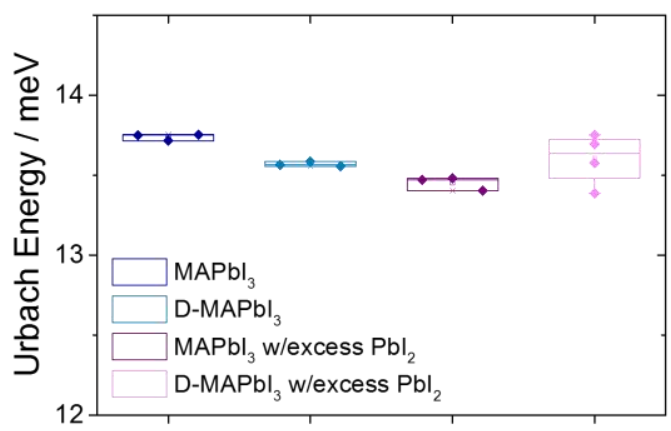




\section{WILEY-VCH}

Figure 2. a) Absorptance, b) reflectance, c) PDS spectra of $\mathrm{MAPbI}_{3}, \mathrm{D}-\mathrm{MAPbI}_{3}, \mathrm{MAPbI}_{3}$ with excess $\mathrm{PbI}_{2}$, and $\mathrm{D}-\mathrm{MAPbI}_{3}$ with excess $\mathrm{PbI}_{2}$ perovskite films (highlighted area in the absorptance spectra denotes the tail at the band edge for degraded samples in log scale), and d) Urbach energies of perovskite films.

To confirm the relation of sub-bandgap absorption and device photocurrent, we conducted Fourier-transform photocurrent spectroscopy (FTPS), as shown in Figure S3. Here, we excited the samples both from the bare surface of the perovskite film and from the glass substrate side. No significant change in the low energy photon region of the FTPS spectra was observed in the case of excitation from the substrate side after the degradation process. Contrary to the PDS results, the samples exposed to humid air under illumination show a passivation effect of the surface of the perovskite. We note that PDS and FTPS are highly sensitive measurement techniques. ${ }^{[19]}$ Yet, they differ in the way 'absorption' is measured. While PDS responds to photons absorbed by the sample, including those absorbed in the substrate, FTPS measures the photocurrent response of the sample, that is, only photons that generate photocurrent in the semiconductor layer are detected. Thus, photons absorbed by the substrate or by the sample, not leading to current do not contribute to the photocurrent spectra. In the case of $\mathrm{MAPbI}_{3}$, the maximum $\mathrm{V}_{\mathrm{OC}}$ reported is $1.19 \mathrm{~V}$ and thus $140 \mathrm{mV}$ lower than its radiative limit of $1.33 \mathrm{~V}$ (1.60 eV bandgap, considering $100 \%$ radiative recombination). ${ }^{[20,21]}$ The voltage losses are related to the electronic quality of bulk of the perovskite, which is usually characterized by its Urbach energy $\left(\mathrm{E}_{\mathrm{U}}\right)$, and the surface (interfacial) recombination. ${ }^{[22,23]}$ Recent studies have revealed that the reported high VOC of PSCs are linked to low $E_{U}$ values. ${ }^{[22]}$ Thus, the $E_{U}$ of the perovskite samples after exposure to humid air under illumination was determined. Here, we calculated the $\mathrm{E}_{\mathrm{U}}$ from PL microspectroscopy (Figure S4) using the reciprocity theorem, since the dynamic range is more than 10 orders allowing for a more precise evaluation of $\mathrm{E}_{\mathrm{U}}:^{[19,24]}$

$$
P L(E) \sim A_{B}(E) E^{2} \exp \left(-\frac{E}{k_{B} T}\right)
$$




\section{WILEY-VCH}

where $A_{B}(E)$ absorptance spectrum (Figure $\mathrm{S} 4 \mathrm{c}$ ), $P L(E)$ is the photoluminescence spectrum, $E$ the photon energy, $k_{B}$ the Boltzmann constant, and $T$ the absolute temperature. Figure $2 \mathrm{~d}$ shows the $E_{U}$ change of the perovskite thin films after exposure to humid air and illumination. We found that exposing the $\mathrm{MAPbI}_{3}$ perovskite to atmospheric conditions under 1-sun conditions slightly lowered the $E_{U}$ from $13.73 \pm 0.02$ to $13.57 \pm 0.02 \mathrm{meV}$; however, this value increased for the perovskite with excess $\mathrm{PbI}_{2}$.
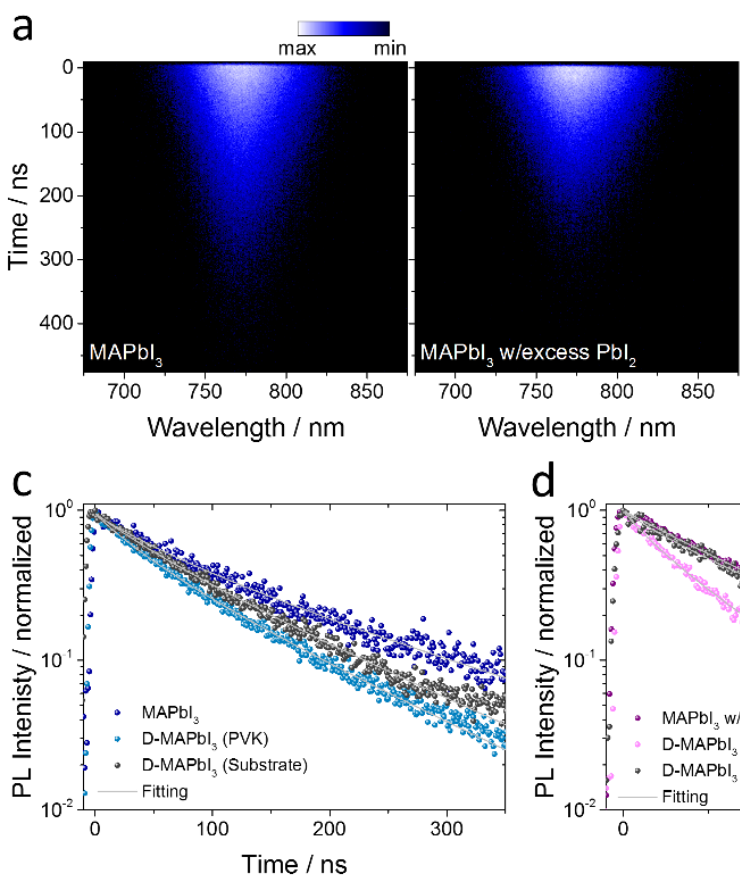
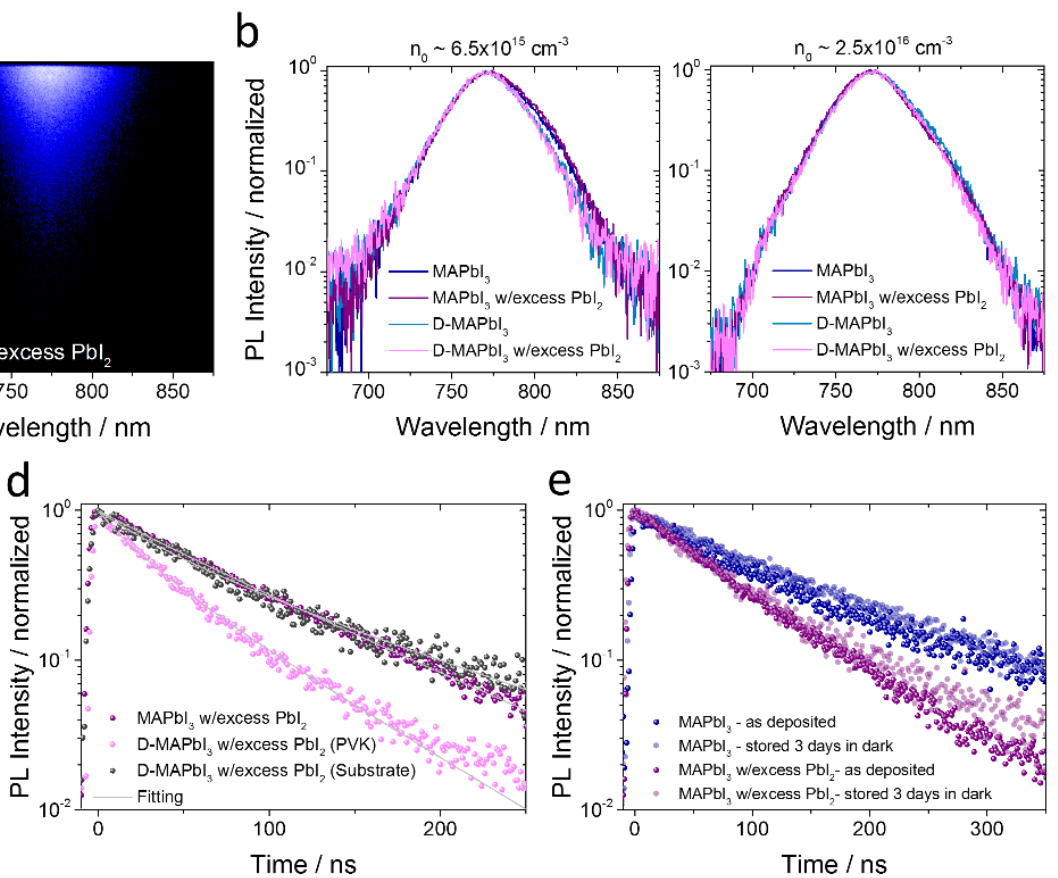

Figure 3. a) 2D pseudo color TRPL plots of $\mathrm{MAPbI}_{3}$ perovskite films (without and with excess $\mathrm{PbI}_{2}$ ), b) and c) PL spectra of perovskite films extracted at $\mathrm{t}=1 \mathrm{~ns}$ from streak camera images for fluence 49 and $194 \mathrm{~nJ} \mathrm{~cm}{ }^{-2}$, respectively. TRPL decay of c) $\mathrm{MAPbI}_{3}$ and $\mathrm{D}-\mathrm{MAPbI}_{3}$ perovskite films, d) $\mathrm{MAPbI}_{3}$ and $\mathrm{D}-\mathrm{MAPbI}_{3}$ with excess $\mathrm{PbI}_{2}$ perovskite films and e) 3 days stored perovskite films (with and without excess $\mathrm{PbI}_{2}$ ) in humid air (RH: 40-50 \%) under dark. All the PL decays probed at $773 \mathrm{~nm}$ with $\sim 29 \mathrm{meV}$ range. The samples excited using $650 \mathrm{~nm}$ wavelength with laser fluence $49 \mathrm{~nJ} \mathrm{~cm} ~^{-2}$ and frequency $250 \mathrm{kHz}$.

To reveal the excited state dynamics of the perovskite films, we conducted time-resolved photoluminescence (TRPL) spectroscopy; results are shown in Figure 3. All measurements were done in nitrogen atmosphere to avoid environmental impact on the PL lifetime, as the PL lifetime can change when exciting in atmospheric conditions (Figure S5). 2D pseudocolour TRPL plots of $\mathrm{MAPbI}_{3}$ and $\mathrm{MAPbI}_{3}$ with excess $\mathrm{PbI}_{2}$ films are presented in 


\section{WILEY-VCH}

Figure 3a, respectively. The PL spectra $\left(t_{\text {delay }}=1 \mathrm{~ns}\right)$ of the reference samples at different injection levels, $n_{0}$, change with increased excitation intensity; however, PL spectra of degraded perovskite films are similar (Figure 3b). Interestingly, spectral narrowing is observed only at the red part of the PL spectrum. We hypothesize that this is a consequence of trap state filling close to the band edge occurring at higher carrier concentrations (Figure S6). We observed an additional 8-10 meV blue shift of the PL spectra (Figure S7) at low excitation intensity (carrier density) in samples exposed to humid air under one-sun illumination. This blue shift can be explained by $\mathrm{Pb}-\mathrm{I}$ bond elongation since photogenerated carriers weaken the covalent bond and cause lattice expansion as direct consequence of radiative heating, which is caused by either elongation of the $\mathrm{Pb}-\mathrm{I}$ bonds (blue-shift in $\mathrm{PL}$ ) or less-distorted $\mathrm{Pb}-\mathrm{I}-\mathrm{Pb}$ bonds (red-shift in PL) after the illumination of the perovskite (650 nm excitation). ${ }^{[25]}$ Furthermore, we examined the PL dynamics of the samples before and after exposure to humid air under one-sun illumination (Figure 3c-d). The PL dynamics were fitted by the general rate equation however, excluding Auger recombination, since this process becomes relevant only at high injection levels, $n_{0}>10^{18} \mathrm{~cm}^{-3}$, in perovskite semiconductors: ${ }^{[20,26]}$

$$
-\frac{d n}{d t}=k_{1} n+k_{2} n^{2}
$$

here, $k_{1}$ and $k_{2}$ represent the trap-assisted nonradiative (monomolecular) and the band-toband radiative recombination rate constants, respectively. The extracted rate constants of the reference and degraded perovskite films are listed in Table 1 . We found that $k_{1}$ is increased by degradation in both perovskite films with and without excess $\mathrm{PbI}_{2}$. While several recent studies have reported passivation by excess $\mathrm{PbI}_{2},{ }^{[27]}$ here the excess $\mathrm{PbI}_{2}$ present in the film reduced the PL lifetime from 171 ns to 144 ns, consistent with the lowered $V_{\text {OC }}$ of devices (Figure 1b-c and S1). Furthermore, to investigate the uniformity of the degradation effect across the perovskite absorber layer, we changed the incident angle of the excitation. ${ }^{[28]} \mathrm{We}$ note that the penetration depth of the laser beam is $\sim 200 \mathrm{~nm}$ for $\mathrm{MAPbI}_{3}$, whereas the sample 


\section{WILEY-VCH}

thickness is $400 \mathrm{~nm}$. We found a more pronounced reduction in PL lifetime by exciting a larger portion of the surface of the perovskite, for the samples exposed to humid air under illumination, especially in the case of $\mathrm{MAPbI}_{3}$ with excess $\mathrm{PbI}_{2}$ (Figure 3c-d). On the other hand, excitation from the quartz glass substrate side of the sample showed no significant difference in the PL lifetime compared to as-deposited perovskite films. This indicates that adsorption of molecules on the surface (or close to surface) has distorted the perovskite structure of the thin film.

Moreover, we stored the perovskite films in dark under atmospheric conditions $(\mathrm{RH}=$ 45-55\%) for three days to investigate the effect of illumination. Under this condition, the PL dynamics of the perovskite films did not show faster recombination (Figure 3e). This, in turn, indicates that not only the steady-state sub-bandgap optical properties change, but also the charge carrier dynamics strongly depend on light exposure. As mentioned, sub-bandgap absorption was not observed for the samples stored in dark for three days in humid air. Therefore, we hypothesize that illumination is one of the critical external stimuli for defect formation, which also leads to sub-bandgap absorption features.

Table 1. Rate constants of PL dynamics of perovskite samples determined by fits to the TR-PL dynamics.

\begin{tabular}{ccc} 
Sample & $\mathbf{k}_{\mathbf{1}}\left(\mathbf{s}^{\mathbf{- 1}}\right)$ & $\mathbf{k}_{\mathbf{2}}\left(\mathbf{c m}^{\mathbf{3}} \mathbf{s}^{\mathbf{- 1}}\right)$ \\
\hline $\mathrm{MAPbI}_{3}$ & $5.2 \times 10^{6}$ & $1.0 \times 10^{-9}$ \\
$\mathrm{D}-\mathrm{MAPbI}_{3}$ & $8.3 \times 10^{6}$ & $1.5 \times 10^{-9}$ \\
\cline { 2 - 3 } $\mathrm{MAPbI}_{3}$ w/excess $\mathrm{PbI}_{2}$ & $1.1 \times 10^{7}$ & $1.0 \times 10^{-10}$ \\
\cline { 2 - 3 } $\mathrm{MAPI}_{3}$ w/excess $\mathrm{PbI}_{2}$ & $1.6 \times 10^{7}$ & $1.0 \times 10^{-10}$ \\
\cline { 2 - 3 }
\end{tabular}

Both steady-state and transient optical measurements revealed noticeable changes after exposure to humid air under illumination. However, revealing the structural changes is crucial to understand the degradation effect. SEM top-view images were taken to examine the surface 


\section{WILEY-VCH}

morphology of the perovskite films, as shown in Figure 4a-b, d-e and Figure S8. The

decomposition of perovskite creating $\mathrm{PbI}_{2}$ occurs first at the grain boundaries but does not start at the surface, as previously reported. ${ }^{[29,30]}$ Moreover, we found that smaller grains have a larger tendency to decompose, as shown in Figure $4 \mathrm{~b}$ and $4 \mathrm{e}$. This can be understood, because grain boundaries act as pathways for diffusion of ionic defects and/or mobile ions. ${ }^{[30]}$ Moreover, ab initio molecular dynamics simulations showed that $\mathrm{MAPbI}_{3}$ perovskite is prone to a rapid solvation process, in which iodine atoms are released by the interaction of water molecules with $\mathrm{Pb}$ atoms within MAI-terminated surfaces. ${ }^{[31]}$
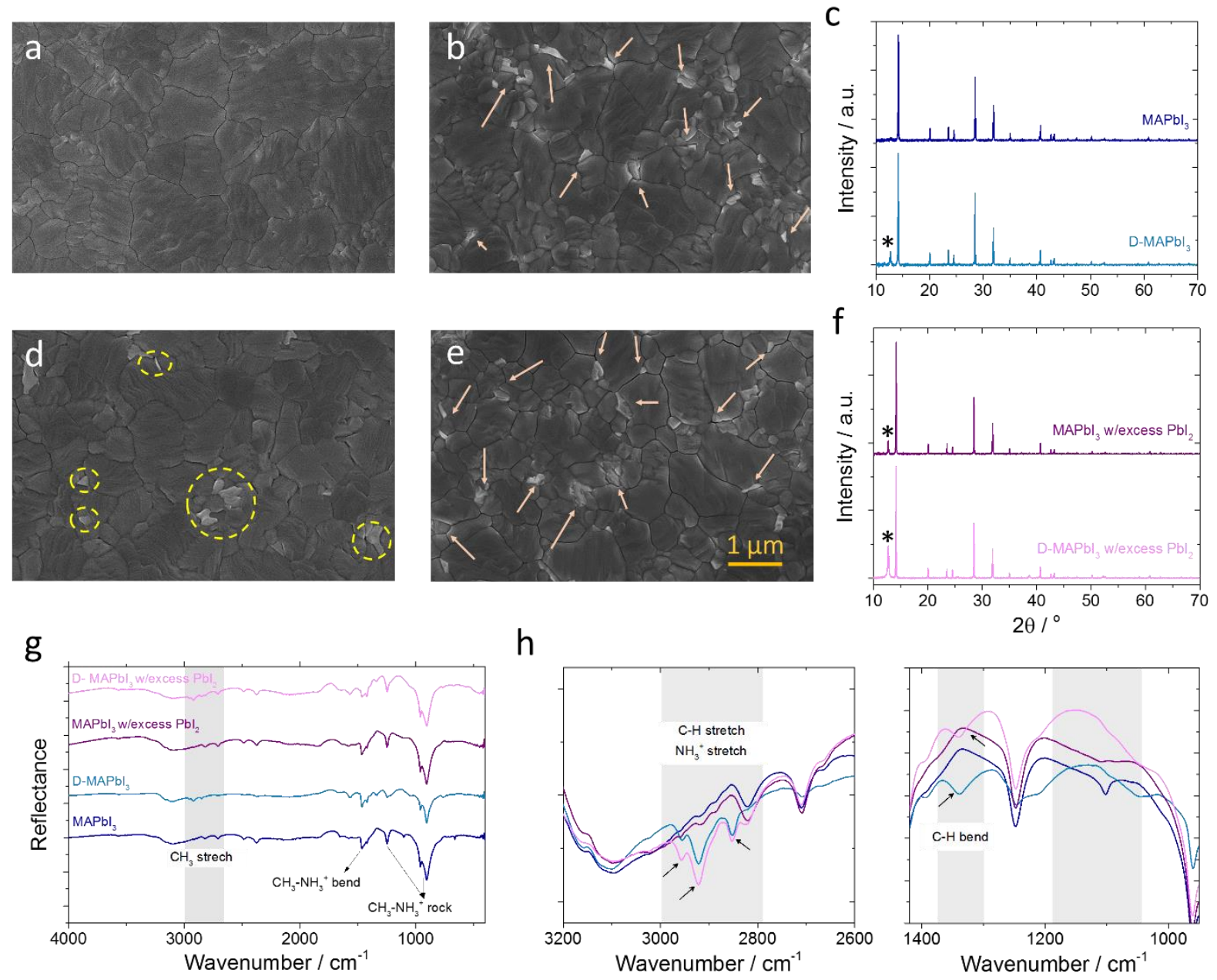

Figure 4. $\mathrm{SEM}$ micrographs of a) $\mathrm{MAPbI}_{3}$, b) $\mathrm{D}-\mathrm{MAPbI}_{3}$, d) $\mathrm{MAPbI}_{3}$ with excess $\mathrm{PbI}_{2}$, and e) $\mathrm{D}-\mathrm{MAPbI}_{3}$ with excess $\mathrm{PbI}_{2}$ perovskite thin films (Scale bar: $1 \mu \mathrm{m}$ ). Circles highlight excess $\mathrm{PbI}_{2}$ in perovskite film shown in d). Arrows in b) and e) indicate the degraded parts in $\mathrm{MAPbI}_{3}$ films which mainly occur between the grains. c), and f) XRD pattern of respective films. Star shows the $\mathrm{PbI}_{2}$ peak around $2 \theta=13^{\circ}$. g) FT-IR spectra of perovskite samples (with and without excess $\mathrm{PbI}_{2}$ ) as-deposited and after degradation process. h) Highlighted areas in FT-IR spectra in $\mathrm{g})$. 


\section{WILEY-VCH}

In Figure 4c and 4f, we compare the X-ray diffraction (XRD) pattern in the Bragg-Brentano configuration (longitudinal) for the perovskite films before and after exposure to humid air under illumination. An increase in the $\mathrm{PbI}_{2}$ peak intensity around $2 \theta=13^{\circ}$ was observed for $\mathrm{MAPbI}_{3}$ film after the degradation process consistent with SEM micrographs. Although the interaction of water molecules with $\mathrm{PbI}_{2}$-terminated surfaces does not accelerate the degradation due to stronger $\mathrm{Pb}-\mathrm{I}$ bonds, $\mathrm{PbI}_{2}$ defects on the $\mathrm{PbI}_{2}$-terminated surface promote the rapid dissolution of the exposed facet. ${ }^{[31]}$ This phenomenon could explain the formation of excess $\mathrm{PbI}_{2}$ that we observed in SEM, XRD, and Raman spectroscopy measurements after exposure to humid air under illumination (Figure 4 and S10). For further investigation, we performed Fourier-transform infrared (FTIR) spectroscopy before and after the degradation process; results are shown in Figure 4g-h. In fact, excess $\mathrm{PbI}_{2}$ in $\mathrm{MAPbI}_{3}$ films did not change the perovskite-associated vibrational peaks in the FTIR spectra, which are mainly the vibrational modes of the organic cations: $\mathrm{CH}_{3}-\mathrm{NH}_{3}{ }^{+}$rocking (906 and $1248 \mathrm{~cm}^{-1}$ ), $\mathrm{C}-\mathrm{N}$ stretching $\left(960 \mathrm{~cm}^{-1}\right), \mathrm{CH}_{3}$ bending $\left(1422 \mathrm{~cm}^{-1}\right)$, and $\mathrm{NH}_{3}$ bending $\left(1467 \mathrm{~cm}^{-1}\right) \cdot[32,33]$ However, exposing perovskite films to the atmosphere under light resulted in frequency shifts of the vibrational modes: $\mathrm{C}-\mathrm{H}$ stretching and $\mathrm{C}-\mathrm{H}$ bending associated with $\mathrm{CH}_{3}{ }^{+}$group of MA cations and $\mathrm{NH}_{3}{ }^{+}$stretching. ${ }^{[33,34]}$ In this regard, the additional vibrational modes around $2900-3000 \mathrm{~cm}^{-1}$ can be attributed to $\mathrm{N}-\mathrm{H}$ vibrations of the highest frequency doublydegenerate $\mathrm{E}$ mode of free MA molecules present in $\mathrm{MAPbI}_{3} \cdot \mathrm{H}_{2} \mathrm{O}$ (Figure $4 \mathrm{~h}$ ). Here, this is the most characteristic signature of hydrogen bonding between MA cations and water $\left(\mathrm{H}_{2} \mathrm{O}\right)$, since the $\mathrm{H}$ vibration is along the $\mathrm{O}-\mathrm{H}-\mathrm{N}$ hydrogen bond in the lowest frequency mode at $2958 \mathrm{~cm}^{-1} \cdot{ }^{[34]}$

In addition to the influence of humidity, the formation of $\mathrm{O}_{2}^{-}$is a widely-reported phenomenon for $\mathrm{MAPbI}_{3}$ perovskite films caused by illumination in the presence of oxygen. ${ }^{[7]}$ 


\section{WILEY-VCH}

According to Aristidou et al., the $\mathrm{O}_{2}^{-}$formation is facilitated by illumination, since the enthalpy of the reaction is $-1.40 \mathrm{eV}$ per $\mathrm{O}_{2}$ molecule, while it is $+1.60 \mathrm{eV}$ in the absence of light: $:^{[7,35]}$

$$
4 \mathrm{CH}_{3} \mathrm{NH}_{3} \mathrm{PbI}_{3} *+\mathrm{O}_{2}^{-} \rightarrow 4 \mathrm{PbI}_{2}+2 \mathrm{I}_{2}+2 \mathrm{H}_{2} \mathrm{O}+4 \mathrm{CH}_{3} \mathrm{NH}_{2}
$$

Moreover, it has been concluded that ionic defects like $V_{I}$ sites are the preferred sites in the crystal for the reduction due to reduced $\mathrm{O}_{2}{ }^{-}$formation energy. On the other hand, the full octahedral coordination of $\mathrm{Pb}_{2}{ }^{+}$is similar, since the $\mathrm{O}_{2}^{-}$has the same ionic size as the iodide ion. ${ }^{[7]}$ Most of the previous studies reported that oxidation of iodide interstitials by exposure to oxygen deactivates deep (hole) traps $;{ }^{[4,13]}$ however, we believe that our findings are better explained by the interaction between water, $\mathrm{O}_{2}$ molecules, and $\mathrm{Pb}-\mathrm{I}$ bonds, consistent with a recently published study by $\mathrm{He}$ et al., indicating that interstitial charged oxygen species degrade the perovskite by breaking $\mathrm{Pb}-\mathrm{I}$ chemical bonds. ${ }^{[8]} \mathrm{We}$ observed a blue shift of the $\mathrm{PL}$, which can be explained by elongation of $\mathrm{Pb}-\mathrm{I}$ bonds; however, FTIR spectra did not show any additional features related to $\mathrm{Pb}-\mathrm{O}$ bonds (around $460-470 \mathrm{~cm}^{-1}$ for $\mathrm{Pb}-\mathrm{O}$ stretching), since $\mathrm{Pb}-\mathrm{O}$ is formed after cleaving of $\mathrm{Pb}-\mathrm{I}$ chemical bonds. ${ }^{[36]}$ Therefore, the drastic change in 94 and $100 \mathrm{~cm}^{-1}$ Raman lines in $\mathrm{MAPbI}_{3}$ with excess $\mathrm{PbI}_{2}$ after degradation can be attributed to enhanced $\mathrm{O}_{2}^{-}$formation compared to the reference sample (Figure $\mathrm{S} 10$ ). The Raman activity of $\mathrm{MAPbI}_{3}$ is weak due to its structural symmetry, ${ }^{[37]}$ and the degradation products change the polarizability tensor in the surrounding perovskite structure, which in turn substantially increases the Raman signal. ${ }^{[7,32]}$ 


\section{WILEY-VCH}

a

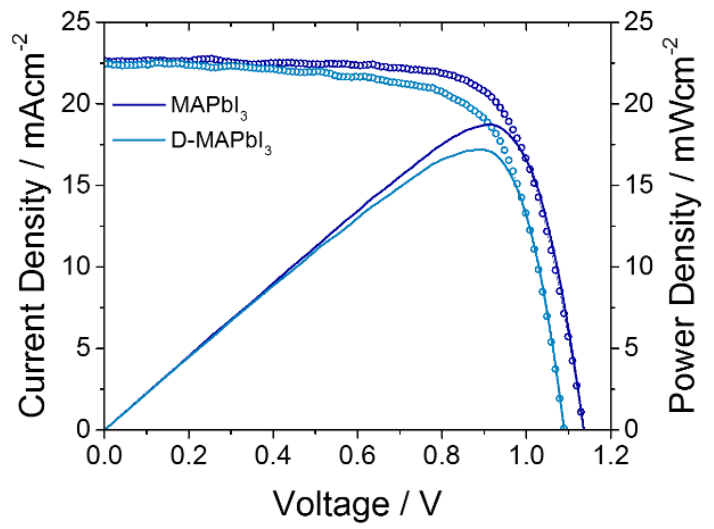

C

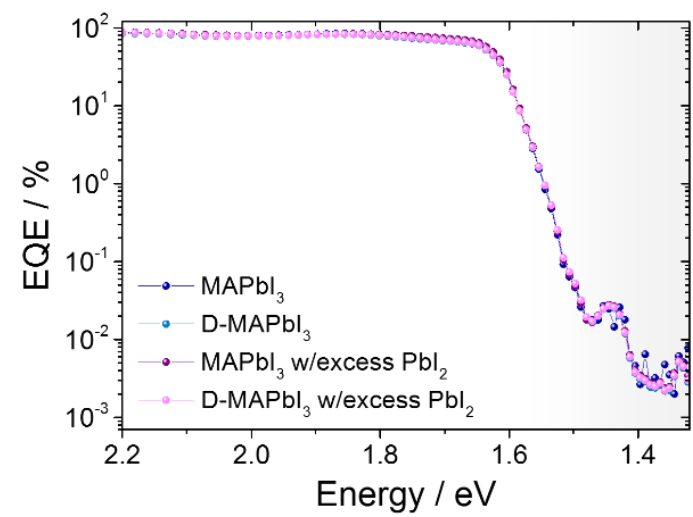

b

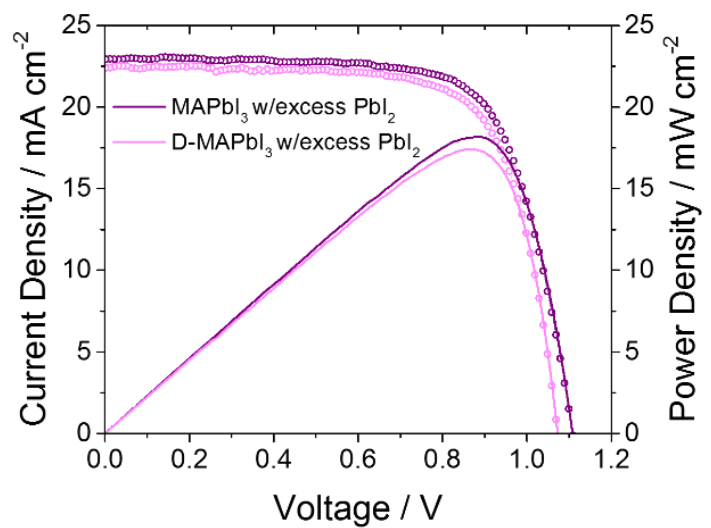

d

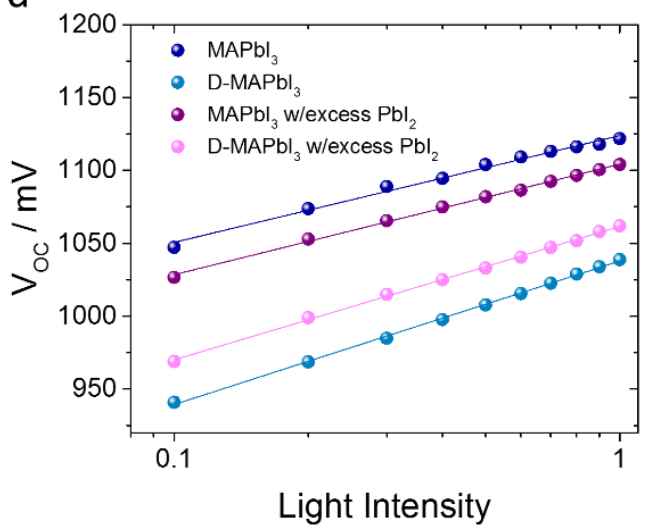

Figure 5. $J-V$ characteristics of $\mathrm{MAPbI}_{3}$ solar cells a) without excess $\mathrm{PbI}_{2}$ and b) with excess $\mathrm{PbI}_{2}$. Perovskite absorber layer exposed to humid air under one-sun illumination for the degradation process before finalizing the device fabrication. c) Sensitive EQE spectra of related photovoltaic devices, and d) light intensity $v s$. VOC plot of solar cells which extracted from light intensity-dependent $J-V$ measurements using PAIOS system. The extracted slopes: 0.073 for $\mathrm{MAPbI}_{3}, 0.098$ for $\mathrm{D}-\mathrm{MAPbI}_{3}$, and 0.075 for $\mathrm{MAPbI}_{3}$ w/excess $\mathrm{PbI}_{2}, 0.092$ for $\mathrm{D}-\mathrm{MAPbI}_{3}$ w/excess $\mathrm{PbI}_{2}$.

Finally, we reveal the effect of perovskite film exposure to humid air under illumination on the photovoltaic device performance. The semi-finished device structure $\mathrm{MAPbI}_{3} / \mathrm{C}_{60^{-}}$ $\mathrm{SAM} / \mathrm{SnO}_{2} / \mathrm{ITO}$ were exposed to humid air and illumination for 1 hour prior to spin-casting of the HTL and evaporation of the Au. We found that the PCE of best working devices was reduced to $17.2 \%$ and $17.4 \%$ for $\mathrm{D}-\mathrm{MAPbI}_{3}$ and $\mathrm{D}-\mathrm{MAPbI}_{3}$ with excess $\mathrm{PbI}_{2}$, respectively, as shown in Figure 5a-b. The device parameters of champion solar cells are listed in Table 2. The main loss in device performance was due to reduced $V_{\text {OC }}$, consistent with our optical analysis (Figure S12, S13 and Table S1). Hence, we conclude that exposure to humid air and illumination increased the trap-assisted recombination rate constant, $k_{1}$, which results in 
additional loss channels for photogenerated carriers leading to lower quasi-Fermi level splitting and thus higher voltage losses, $\mathrm{W}_{\mathrm{OC}}{ }^{[22,38]}$

Table 2. $J-V$ characteristic of champion $\mathrm{MAPbI}_{3}$ perovskite solar cells.*

\begin{tabular}{cccccc} 
Sample & $\begin{array}{c}\boldsymbol{J S C} \\
\left(\mathbf{m A ~ c m} \mathbf{~}^{-2}\right)\end{array}$ & $\begin{array}{c}\boldsymbol{V O C} \\
(\mathbf{m V})\end{array}$ & $\boldsymbol{F F}$ & $\begin{array}{c}\boldsymbol{\eta} \\
(\boldsymbol{\%})\end{array}$ & $\begin{array}{c}\text { Scan } \\
\text { direction }\end{array}$ \\
\hline $\mathrm{MAPbI}_{3}$ & 22.64 & 1136 & 0.73 & 18.73 & Reverse \\
& 22.75 & 1118 & 0.73 & 18.50 & Forward \\
\hline $\mathrm{D}^{2} \mathrm{MAPbI}_{3}$ & 22.50 & 1090 & 0.70 & 17.20 & Reverse \\
& 22.58 & 1095 & 0.70 & 17.29 & Forward \\
\hline $\mathrm{MAPbI}_{3}$ w/excess $\mathrm{PbI}_{2}$ & 22.96 & 1109 & 0.71 & 18.17 & Reverse \\
& 22.97 & 1104 & 0.70 & 17.67 & Forward \\
\hline \multirow{2}{*}{$\mathrm{D}-\mathrm{MAPbI}_{3}$ w/excess $\mathrm{PbI}_{2}$} & 22.49 & 1073 & 0.72 & 17.42 & Reverse \\
& 22.56 & 1070 & 0.71 & 17.24 & Forward \\
\hline
\end{tabular}

*All devices were tested at $50 \mathrm{mV} \mathrm{s}^{-1}$ scan rate without any preconditioning.

To further characterize the losses in devices, light intensity-dependent $J-V$ measurements were performed (Figure 5d and S14). Here, we used the commercial PAIOS system (Fluxim) to investigate the change in $\mathrm{V}_{\mathrm{OC}}$ upon changing the illumination intensity. While we cannot quantify $k_{B} T / q$ due to the PAIOS spectrum, we found that the slope of the $\mathrm{V}_{\mathrm{OC}}$ vs. light intensity increased for the samples exposed to humid air and illumination. This indicates increased non-radiative recombination in the degraded samples and in the samples with excess $\mathrm{PbI}_{2}$ compared to pristine $\mathrm{MAPbI}_{3}$. Furthermore, to investigate the effect of subbandgap absorption, we conducted sensitive-EQE (sEQE) measurements (Figure 5c) on devices. The sEQE spectra of all samples are virtually the same, and no additional contribution was observed in the degraded samples in the sub-bandgap region (tail region of the band-edge). Therefore, we conclude that moisture and oxygen molecules adsorbed on the surface of the perovskite in which the defects are created simultaneously under continuous 


\section{WILEY-VCH}

illumination are the reason for the sub-bandgap absorption observed by PDS. Furthermore, the distorted perovskite lattice, inducing local strain (Figure S11), and the presence of substitutional atoms due to the exposure to humid air and simultaneous illumination caused enhanced non-radiative recombination, leading to lower device performance. ${ }^{[39]}$ For long-term device stability, along with improved contact quality, excess $\mathrm{PbI}_{2}$ content in perovskite needs to be investigated carefully since under continuous illumination $\mathrm{PbI}_{2}$ undergoes metallic $\mathrm{Pb}$ and $\mathrm{I}_{2}$ via photolysis in which metallic $\mathrm{Pb}$ acts as quencher for carriers and lowers the performance of the devices. ${ }^{[40]}$

\section{Conclusion}

In conclusion, we demonstrated the impact of exposure to humidity and illumination of $\mathrm{MAPbI}_{3}$ perovskite samples with and without excess $\mathrm{PbI}_{2}$ on the device performance and photophysical properties. The device performance was reduced due to increased $V_{\text {OC }}$ losses, which correlates with increased non-radiative recombination. Steady-state absorption measurements showed enhanced sub-bandgap absorption below the band edge of the perovskite. The structural properties of the perovskite films were investigated. Additional vibrational modes around 2900-3000 $\mathrm{cm}^{-1}$ were observed in FTIR spectra, they indicate hydrogen bond formation between $\mathrm{MA}^{+}$cations and $\mathrm{H}_{2} \mathrm{O}$ molecules. We hypothesize that the origin is the combination of adsorbed water molecules from humid air and the product of $\mathrm{O}_{2}{ }^{-}$ formation. Since the iodide is one of the most critical parameters that determines the defect physics in perovskite, $\mathrm{O}_{2}^{-}$formation appears to be the dominant process during exposure to environmental conditions under illumination. Towards this end, we found that trap-assisted non-radiative recombination increased in the case of excitation incident on the surface of the perovskite films. Moreover, $\mathrm{MAPb}_{3}$ samples with excess $\mathrm{PbI}_{2}$ showed more pronounced $\mathrm{PL}$ lifetime changes. Our study reveals that extrinsic effects change the perovskite structure, in turn leading to reduced PL lifetimes and thus lower device performance. Finally, we found 


\section{WILEY-VCH}

that the device performance when using $\mathrm{MAPbI}_{3}$ as active layer is more sensitive to humid air and illumination, which seems to be caused by reduced quality of the interface between perovskite and spiro-OMeTAD.

\section{Experimental Section}

Sample Preparation and Device Fabrication: The substrates for device fabrication (patterned indium tin oxide (ITO) substrates, Xinyan Technology Ltd.) and optical characterization (UVgrade quartz glass, Präzisions Glas \& Optik $\mathrm{GmbH}$ ) were cleaned with detergent first and followed with acetone, and IPA using sonication for $10 \mathrm{~min}$. Before any deposition, the ascleaned substrates treated with $\mathrm{UV}-\mathrm{O}_{3}$ for $10 \mathrm{~min}$.

The compact tin oxide $\left(\mathrm{SnO}_{2}\right)$ layer was deposited on cleaned ITO substrates by spin coating at $3000 \mathrm{rpm}$ for $30 \mathrm{~s}$ using a diluted $\mathrm{SnO}_{2}$ nanoparticle suspension in water (Alfa Aesar, 15\% in $\mathrm{H}_{2} \mathrm{O}$ colloidal dispersion) following the previously reported recipe. ${ }^{[16]}$ After annealing of the $\mathrm{SnO}_{2}$ layer at $150{ }^{\circ} \mathrm{C}, \mathrm{C}_{60}$-based self-assembled monolayer $\left(\mathrm{C}_{60}\right.$ - $\mathrm{COOH}-\mathrm{SAM}$, Luminescence Technology Corp.) dissolved in chlorobenzene and was deposited on $\mathrm{SnO}_{2}$ following the previously reported recipe. ${ }^{[41]}$ The $\mathrm{MAPbI}_{3}$ perovskite absorber layer was fabricated on $\mathrm{C} 60-\mathrm{SAM} / \mathrm{SnO}_{2}$ electron transport layer using our previously reported glycol ether modified 2-step interdiffusion method. ${ }^{[15]}$ In this study, we modified the process with an increased concentration of the solutions as $1.1 \mathrm{M} \mathrm{PbI}_{2}$ in DMF and $44 \mathrm{mg} / \mathrm{mL}$ MAI in IPA, which resulted in $350 \mathrm{~nm}$-thick absorber layers. After the spin coating of the perovskite thin films, samples were annealed at $105^{\circ} \mathrm{C}$ for $40 \mathrm{~min}$. The samples were annealed at a higher temperature at $135{ }^{\circ} \mathrm{C}$ for $15 \mathrm{~min}$ to obtain excess $\mathrm{PbI}_{2}$ in perovskite films. A Spiro-OMeTAD hole transport layer was spun on perovskite absorber layers using precursor solution prepared by dissolving 72.5 mg Spiro-OMeTAD (Luminescence Technology Corp.), $28.5 \mu \mathrm{L}$ 4-tertbutylpyridine (Sigma Aldrich) and $17.5 \mu \mathrm{L}$ of lithium bis(trifluoromethanesulfonyl)imide stock solution in $1 \mathrm{~mL}$ Chlorobenzene. ${ }^{[42]}$ After spin-coating the HTL, the samples were 


\section{WILEY-VCH}

placed in dry air using a humidity-control box for overnight to ensure sufficient oxidation of the Spiro-OMeTAD film. To finalize the device fabrication, $90 \mathrm{~nm}$ Au contacts were thermally evaporated with a deposition rate of $0.2 \AA / \mathrm{sec}$ for the initial $15 \mathrm{~nm}$ and finalized with a rate of $1.00 \AA / \mathrm{sec}$.

For degradation of the perovskite absorber layers, as deposited free standing perovskite films on glass (or $\mathrm{C}_{60}-\mathrm{SAM} / \mathrm{SnO}_{2} / \mathrm{ITO}$ ) were exposed to 1-sun illumination using a solar simulator (Abet Technologies Sun 3000 Solar Simulator) in the ambient atmosphere (40-50\% relative humidity) for $60 \mathrm{~min}$. It is important to note here that during this process the sample temperature could increase up to $\sim 30-40{ }^{\circ} \mathrm{C}$ due to the radiative heating. The perovskite films directly moved to the nitrogen-filled glovebox after degradation process either to store the samples to finalize the devices.

Photovoltaic Device Characterization: The current density-voltage $(J-V)$ characteristics of perovskite solar cells were measured in a nitrogen-purged glovebox under standard simulated AM1.5 illumination using a solar simulator (Abet Technologies Sun 3000 Solar Simulator) equipped with Autolab Potentiostat/Galvanostat. The light intensity was calibrated using a certified reference cell (RERA Solutions, calibrated at Radboud University Nijmegen). All J$V$ curves were tested at $50 \mathrm{mV} / \mathrm{s}$ scan rate both in reverse scan ( $\mathrm{V}_{\mathrm{OC}}$ to $\mathrm{J}_{\mathrm{SC}}, 1.2 \mathrm{~V} \rightarrow-0.1 \mathrm{~V}$ ) and forward scan ( $\mathrm{J}_{\mathrm{SC}}$ to $\mathrm{V}_{\mathrm{OC}},-0.1 \mathrm{~V} \rightarrow 1.2 \mathrm{~V}$ ). No preconditioning protocol has been used before the measurement.

The external quantum efficiency (EQE) measurements were conducted in the air using commercial EQE system (Newport) under dark conditions and without any biasing or preconditioning. Note that the calibration of the EQE was performed by a silicon diode before the measurement.

Transient Photocurrent Measurements: The transient photocurrent (TPC) measurements were collected using the all-in-one measurement system PAIOS 3.2 (Fluxim). PAIOS exploits a 


\section{WILEY-VCH}

first function generator to control the light source (a white LED with a rise/fall time of 100 ns), and a second function generator to control the applied voltage bias. The output current is measured through a trans-impedance amplifier. The white LED (100 mA) has been calibrated with a certified silicon reference (RERA Solutions). 1-sun is referred to as the LED intensity that matches the current of the reference cell with that one obtained through the solar simulator. ${ }^{[43]}$

Sensitive External Quantum Efficiency (s-EQE) Measurements: The EQE spectra were collected at short-circuit under focused monochromatic illumination from a Xenon arc lamp. The light beam was modulated by an optical chopper $(275 \mathrm{~Hz})$. The device output current was measured as a function of incident photon energy using a lock-in amplifier (Stanford Instruments SR 830). The lamp intensity was calibrated with Ge and Si photo-diodes. X-ray Diffraction Measurements: X-ray diffraction (XRD) patterns were obtained using Bruker D8 Advance X-ray diffractometer $\left(\mathrm{Cu}-\mathrm{K}_{\alpha 1}\right.$ radiation, $\left.\lambda=1.5406 \AA\right)$ from 10 to $60^{\circ}(2 \theta)$ with a scan speed of $3 \% \mathrm{~min}$.

Scanning Electron Microscopy: Surface and cross-sectional scanning electron microscopy (SEM) images of the samples were investigated with Carl Zeiss AURIGA® CrossBeam ${ }^{\circledR}$ Workstation using the in-lens detector. The electron acceleration voltage was $5 \mathrm{kV}$, and the working distance was $6 \mathrm{~mm}$.

Fourier Transform Infrared Spectroscopy: Fourier Transform Infrared (FT-IR) spectroscopy measurements were performed on the powder of perovskite film using Cary 600 Series FTIR spectrometer (Agilent Technologies) equipped with attenuated total reflectance PIKE GladiATRTM. Perovskite films were scratched off for FT-IR measurements which performed in the ambient atmosphere.

Ultraviolet-Visible Absorption Spectroscopy: The transmittance (T) and reflectance (R) of the perovskite samples were obtained between 300 and 900 nm using Perkin Elmer Lambda 950 


\section{WILEY-VCH}

UV-vis-NIR spectrophotometer equipped with an integrated sphere. Absorptance of the films calculated by $A=1-(T+R)$.

Photothermal Deflection Spectroscopy: To study the effect of exposure to humid air under illumination, photothermal deflection spectroscopy (PDS) measurements were performed using a home-built PDS setup. The perovskite samples were deposited on $12 \times 8 \mathrm{~mm}^{2}$ quartz substrates in the nitrogen-filled glovebox and immersed in a chemically inert liquid (SigmaAldrich Perfluorohexane $\mathrm{C}_{6} \mathrm{~F}_{14}$ ) for the measurement. The light from a $250 \mathrm{~W}$ quartz-tungstenhalogen lamp (Newport 66996-250Q-R1) was sent through a monochromator (LOT MSH300). The pump light (set to $150 \mathrm{~W}$ ) was modulated by a chopper operating at a constant frequency of $4 \mathrm{~Hz}$ and focused on the sample. A small fraction of the monochromatic pump light was split off as intensity reference and measured by lock-in detection (Stanford Research Systems SR830 lock-in amplifier) using a pyroelectric detector (Newport DET-L-PYC5-R-P). A stabilized CW-laser (Thorlabs HR S015 HeNe 633nm) was used as the probe beam source focused closer to the sample surface. The deviation of the probe beam was detected by a pyro quadrant detector (Thorlabs PDQ80A) using lock-in detection (Stanford Research Systems SR830). The entire setup was controlled by a home-built LabView-based data acquisition and device control code. The PDS spectra were set to an absolute scale by matching the spectra with integrating sphere measurements on a Perkin Elmer Lambda 950 UV-vis-NIR spectrophotometer.

Fourier-Transform Photocurrent Spectroscopy: The absorption spectra are obtained using Fourier-transform photocurrent spectroscopy (FTPS) ${ }^{[1]}$ This method detects a photoconductivity response upon illumination modulated by a Thermo Nicolet 8700 FTIR spectrophotometer, at a scan speed of $0.16 \mathrm{~cm} / \mathrm{s}$. The probe beam illuminating the sample is the white light from a halogen lamp (intensity of approximately $50 \mathrm{~mW} \mathrm{~cm}{ }^{-2}$, i.e. 0.5 suns). Photoluminescence Spectroscopy: The photoluminescence (PL) and Raman spectra are measured in a Renishaw REFLEX micro-spectroscope using $442 \mathrm{~nm}$ and $1064 \mathrm{~nm}$ excitation 


\section{WILEY-VCH}

lasers, respectively. Raman laser is not absorbed in the perovskite film; therefore, the degradation and PL signal background signal is ruled out in this case. On the other hand, the InGaAs detector has to be used for the detection of Raman spectra. The intensity of the PL excitation is reduced to the equivalent (in terms of photon count) of about 2 suns, in order to prevent any structural degradation occurring during the measurements. ${ }^{[37]}$ Due to the absorption/emission reciprocity, absorption spectra are calculated from the measured PL spectra. This absorption detection method is highly sensitive and allows us to determine the Urbach energy precisely. ${ }^{[19]}$

Time-Resolved Photoluminescence Spectroscopy: Time-Resolved Photoluminescence (TRPL) measurements were conducted using a high-resolution streak camera system (Hamamatsu, C10910). The excitation beam was generated from an optical parametric oscillator (OPO) (Inspire OPO, Radiantis) pumped by a femtosecond oscillator (Spectra Physics Mai Tai) at a wavelength of $830 \mathrm{~nm}$. The beam was routed through a pulse picker (pulseSelect, A.P.E) for repetition rate division. The excitation beam at $650 \mathrm{~nm}$ was focused to pump the perovskite samples, mounted inside the sealed chamber. The associated PL emission was spectrally and temporally resolved using a spectrograph and streak camera system. The photogenerated carrier concentration at $\mathrm{t}=0$ was calculated using the formula: ${ }^{[26]}$

$$
n_{0}=\frac{\alpha \cdot f}{E_{\text {photon }}}
$$

where $\alpha$ is the absorption coefficient at the excitation wavelength, $f$ is the fluence of the laser and $E_{\text {photon }}$ is the photon energy.

Perovskite thin films for TR-PL spectroscopy measurements were deposited on cleaned quartz substrates using the same protocol as used for the device fabrication. After deposition of the layers, samples were placed in a sealed nitrogen chamber to prevent any changes due to exposure to oxygen and humidity. All measurements were done at room temperature. 


\section{WILEY-VCH}

\section{Supporting Information}

Supporting Information is available from the Wiley Online Library or from the author.

\section{Acknowledgements}

This publication is based upon work supported by the King Abdullah University of Science and Technology (KAUST) Office of Sponsored Research (OSR) under Award No: OSR2018-CARF/CCF-3079. E. Ugur and F. Laquai thank K. Vandewal and M. Baier for contributing to the setup for photothermal deflection spectroscopy (PDS). M. Ledinský and A. Vlk acknowledge the support of Czech Science Foundation Project No. 17-26041Y, Operational Programme Research, Development, and Education financed by the European Structural and Investment Funds and the Czech Ministry of Education, Youth and Sports (Project No. CZ.02.1.01/0.0/0.0/16_019/0000760 - SOLID21.

Received: ((will be filled in by the editorial staff))

Revised: ((will be filled in by the editorial staff)) Published online: ((will be filled in by the editorial staff)) 


\section{WILEY-VCH}

References

[1] S. De Wolf, J. Holovsky, S.-J. Moon, P. Löper, B. Niesen, M. Ledinsky, F.-J. Haug, J.-H. Yum, C. Ballif, J. Phys. Chem. Lett. 2014, 5, 1035.

[2] S. D. Stranks, G. E. Eperon, G. Grancini, C. Menelaou, M. J. P. Alcocer, T. Leijtens, L. M. Herz, A. Petrozza, Henry J. Snaith, Science 2013, 342, 341; Y. Wang, Y. Zhang, P. Zhang, W. Zhang, Phys. Chem. Chem. Phys. 2015, 17, 11516; Q. Lin, A. Armin, R. C. R. Nagiri, P. L. Burn, P. Meredith, Nat. Photonics 2014, 9, 106.

[3] A. Kojima, K. Teshima, Y. Shirai, T. Miyasaka, J. Am. Chem. Soc. 2009, 131, 6050; NREL, Best Research-Cell Efficiency Chart. https://www.nrel.gov/pv/assets/pdfs/bestresearch-cell-efficiencies.20200311.pdf, accessed: April, 2020.

[4] S. G. Motti, D. Meggiolaro, S. Martani, R. Sorrentino, A. J. Barker, F. De Angelis, A. Petrozza, Adv. Mater. 2019, 0, 1901183; J. S. W. Godding, A. J. Ramadan, Y.-H. Lin, K. Schutt, H. J. Snaith, B. Wenger, Joule 2019, 3, 2716.

[5] J. F. Galisteo-López, M. Anaya, M. E. Calvo, H. Míguez, J. Phys. Chem. Lett. 2015, 6, 2200; J. Jankowska, R. Long, O. V. Prezhdo, ACS Energy Lett. 2017, 2, 1588; Z. Song, A. Abate, S. C. Watthage, G. K. Liyanage, A. B. Phillips, U. Steiner, M. Graetzel, M. J. Heben, Adv. Energy Mater. 2016, 6, 1600846; J. Huang, S. Tan, P. D. Lund, H. Zhou, Energy Environ. Sci. 2017, 10, 2284; M. Anaya, J. F. Galisteo-López, M. E. Calvo, J. P. Espinós, H. Míguez, J. Phys. Chem. Lett. 2018, 9, 3891.

[6] R. Brenes, C. Eames, V. Bulović, M. S. Islam, S. D. Stranks, Adv. Mater. 2018, 30, 1706208.

[7] N. Aristidou, C. Eames, I. Sanchez-Molina, X. Bu, J. Kosco, M. S. Islam, S. A. Haque, Nat. Commun. 2017, 8, 15218.

[8] J. He, W.-H. Fang, R. Long, O. V. Prezhdo, J. Am. Chem. Soc. 2020, 142, 14664. 


\section{WILEY-VCH}

[9] S. Pathak, A. Sepe, A. Sadhanala, F. Deschler, A. Haghighirad, N. Sakai, K. C.

Goedel, S. D. Stranks, N. Noel, M. Price, S. Hüttner, N. A. Hawkins, R. H. Friend, U. Steiner, H. J. Snaith, ACS Nano 2015, 9, 2311.

[10] G. E. Eperon, S. N. Habisreutinger, T. Leijtens, B. J. Bruijnaers, J. J. v. Franeker, D.

W. deQuilettes, S. Pathak, R. J. Sutton, G. Grancini, D. S. Ginger, R. A. J. Janssen, A.

Petrozza, H. J. Snaith, ACS Nano 2015, 9, 9380.

[11] J. Yang, B. D. Siempelkamp, D. Liu, T. L. Kelly, ACS Nano 2015, 9, 1955.

[12] J. A. Christians, P. A. M. Herrera, P. V. Kamat, J. Am. Chem. Soc. 2015, 137, 1530.

[13] D. Meggiolaro, E. Mosconi, F. De Angelis, ACS Energy Lett. 2017, 2, 2794.

[14] R. Brenes, D. Guo, A. Osherov, N. K. Noel, C. Eames, E. M. Hutter, S. K. Pathak, F.

Niroui, R. H. Friend, M. S. Islam, H. J. Snaith, V. Bulovi, T. J. Savenije, S. D. Stranks, Joule 2017, $1,155$.

[15] E. Ugur, A. D. Sheikh, R. Munir, J. I. Khan, D. Barrit, A. Amassian, F. Laquai, ACS Energy Lett. 2017, 2, 1960.

[16] Q. Jiang, L. Zhang, H. Wang, X. Yang, J. Meng, H. Liu, Z. Yin, J. Wu, X. Zhang, J. You, Nat. Energy 2016, 2, 16177.

[17] B.-W. Park, N. Kedem, M. Kulbak, D. Y. Lee, W. S. Yang, N. J. Jeon, J. Seo, G. Kim, K. J. Kim, T. J. Shin, G. Hodes, D. Cahen, S. I. Seok, Nat. Commun. 2018, 9, 3301; T. Meier, T. P. Gujar, A. Schönleber, S. Olthof, K. Meerholz, S. van Smaalen, F. Panzer, M. Thelakkat, A. Köhler, J. Mater. Chem. C 2018, 6, 7512; T. P. Gujar, T. Unger, A. Schönleber, M. Fried, F. Panzer, S. van Smaalen, A. Köhler, M. Thelakkat, Phys. Chem. Chem. Phys. 2018, 20, 605.

[18] N. Kavcar, Sol. Energy Mater. Sol. Cells 1998, 52, 183.

[19] M. Ledinsky, T. Schönfeldová, J. Holovský, E. Aydin, Z. Hájková, L. Landová, N. Neyková, A. Fejfar, S. De Wolf, J. Phys. Chem. Lett. 2019, 10, 1368.

[20] W. Tress, Adv. Energy Mater. 2017, 7, 1602358. 


\section{WILEY-VCH}

[21] J. Ávila, C. Momblona, P. Boix, M. Sessolo, M. Anaya, G. Lozano, K. Vandewal, H.

Míguez, H. J. Bolink, Energy Environ. Sci. 2018, 11, 3292.

[22] E. Aydin, M. De Bastiani, S. De Wolf, Adv. Mater. 2019, 31, 1900428.

[23] Y. Yang, M. Yang, David T. Moore, Y. Yan, Elisa M. Miller, K. Zhu, Matthew C.

Beard, Nat. Energy 2017, 2, 16207.

[24] C. Barugkin, J. Cong, T. Duong, S. Rahman, H. T. Nguyen, D. Macdonald, T. P.

White, K. R. Catchpole, J. Phys. Chem. Lett. 2015, 6, 767.

[25] H. Tsai, R. Asadpour, J.-C. Blancon, C. C. Stoumpos, O. Durand, J. W. Strzalka, B.

Chen, R. Verduzco, P. M. Ajayan, S. Tretiak, J. Even, M. A. Alam, M. G. Kanatzidis, W. Nie, A. D. Mohite, Science 2018, 360, 67; N. Rolston, R. Bennett-Kennett, L. T. Schelhas, J. M. Luther, J. A. Christians, J. J. Berry, R. H. Dauskardt, Science 2020, 368, eaay8691.

[26] J. M. Richter, M. Abdi-Jalebi, A. Sadhanala, M. Tabachnyk, J. P. H. Rivett, L. M. Pazos-Outón, K. C. Gödel, M. Price, F. Deschler, R. H. Friend, Nat. Commun. 2016, 7, 13941.

[27] J. I. Khan, A. D. Sheikh, M. A. Alamoudi, D. Barrit, E. Ugur, F. Laquai, A. Amassian, Energy Technol. 2020, 8, 1900627; L. Wang, C. McCleese, A. Kovalsky, Y. Zhao, C. Burda, J. Am. Chem. Soc. 2014, 136, 12205; T. J. Jacobsson, J.-P. Correa-Baena, E. H. Anaraki, B. Philippe, S. D. Stranks, M. E. F. Bouduban, W. Tress, K. Schenk, J. Teuscher, J.-E. Moser, H. Rensmo, A. Hagfeldt, J. Am. Chem. Soc. 2016, 138, 10331.

[28] E. Ugur, J. I. Khan, E. Aydin, M. Wang, M. Kirkus, M. Neophytou, I. McCulloch, S. De Wolf, F. Laquai, J. Phys. Chem. Lett. 2019, 10, 6921.

[29] Q. Wang, B. Chen, Y. Liu, Y. Deng, Y. Bai, Q. Dong, J. Huang, Energy Environ. Sci. 2017, $10,516$.

[30] J. S. Yun, J. Kim, T. Young, R. J. Patterson, D. Kim, J. Seidel, S. Lim, M. A. Green, S. Huang, A. Ho-Baillie, Adv. Funct. Mater. 2018, 28, 1705363.

[31] E. Mosconi, J. M. Azpiroz, F. De Angelis, Chem. Mater. 2015, 27, 4885. 


\section{WILEY-VCH}

[32] J. Padchasri, R. Yimnirun, J. Alloys Compd. 2017, 720, 63.

[33] J. Idígoras, A. Todinova, J. R. Sánchez-Valencia, A. Barranco, A. Borrás, J. A. Anta, Phys. Chem. Chem. Phys. 2016, 18, 13583.

[34] Z. Zhu, V. G. Hadjiev, Y. Rong, R. Guo, B. Cao, Z. Tang, F. Qin, Y. Li, Y. Wang, F. Hao, S. Venkatesan, W. Li, S. Baldelli, A. M. Guloy, H. Fang, Y. Hu, Y. Yao, Z. Wang, J. Bao, Chem. Mater. 2016, 28, 7385.

[35] N. Aristidou, I. Sanchez-Molina, T. Chotchuangchutchaval, M. Brown, L. Martinez, T. Rath, S. A. Haque, Angew. Chem., Int. Ed. 2015, 54, 8208.

[36] C. Zheng, O. Rubel, J. Phys. Chem. C 2019, 123, 19385; Y. Ouyang, Y. Li, P. Zhu, Q. Li, Y. Gao, J. Tong, L. Shi, Q. Zhou, C. Ling, Q. Chen, Z. Deng, H. Tan, W. Deng, J. Wang, J. Mater. Chem. A 2019, 7, 2275; K. T. Arulmozhi, N. Mythili, AIP Adv. 2013, 3, 122122.

[37] M. Ledinský, P. Löper, B. Niesen, J. Holovský, S.-J. Moon, J.-H. Yum, S. De Wolf, A. Fejfar, C. Ballif, J. Phys. Chem. Lett. 2015, 6, 401.

[38] S. D. Stranks, ACS Energy Lett. 2017, 2, 1515.

[39] S. Jariwala, H. Sun, G. W. P. Adhyaksa, A. Lof, L. A. Muscarella, B. Ehrler, E. C. Garnett, D. S. Ginger, Joule 2019, 3, 3048.

[40] G. Tumen-Ulzii, C. Qin, D. Klotz, M. R. Leyden, P. Wang, M. Auffray, T. Fujihara, T. Matsushima, J.-W. Lee, S.-J. Lee, Y. Yang, C. Adachi, Adv. Mater. 2020, 32, 1905035; C. Qin, T. Matsushima, T. Fujihara, W. J. Potscavage Jr., C. Adachi, Adv. Mater. 2016, 28, 466. [41] Y. Sun, C. Wang, D. Zhao, J. Yu, X. Yin, C. R. Grice, R. A. Awni, N. Shrestha, Y. Yu, L. Guan, R. J. Ellingson, W. Tang, Y. Yan, Sol. RRL 2018, 2, 1700175.

[42] J. Peng, J. I. Khan, W. Liu, E. Ugur, T. Duong, Y. Wu, H. Shen, K. Wang, H. Dang, E. Aydin, X. Yang, Y. Wan, K. J. Weber, K. R. Catchpole, F. Laquai, S. De Wolf, T. P. White, Adv. Energy Mater. 2018, 8, 1801208. 


\section{WILEY-VCH}

[43] M. De Bastiani, E. Aydin, T. Allen, D. Walter, A. Fell, J. Peng, N. Gasparini, J.

Troughton, D. Baran, K. Weber, T. P. White, S. De Wolf, Adv. Electron. Mater. 2019, 5, 1800500. 


\section{WILEY-VCH}

How Humidity and Light Exposure Change the Photophysics of Metal Halide Perovskite Solar Cells

Esma Ugur, * Erkki Alarousu, Jafar I. Khan, Aleš Vlk, Erkan Aydin, Michele De Bastiani, Ahmed H. Balawi, Sandra P. Gonzalez-Lopez, Martin Ledinský, Stefaan De Wolf, and Frédéric Laquai*

\section{ToC figure}

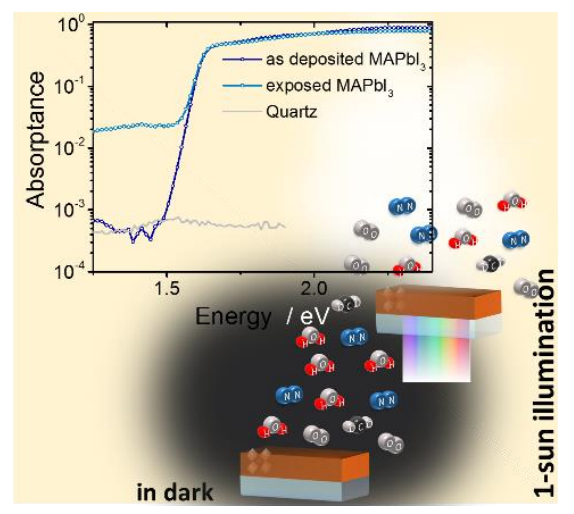

Exposing metal halide perovskite thin films to humid air under illumination induces subbandgap defect states and increases trap-assisted carrier recombination, while in the dark, neither are the carrier dynamics changed nor are sub-bandgap defect states formed. Thus, light-activated defect formation is the origin of photovoltage losses, caused by degradation of the perovskite/spiro-OMeTAD interface in $n-i-p$ metal halide perovskite solar cells.

Keywords: metal-halide perovskites, perovskite solar cells, perovskite photophysics, photodegradation 


\section{WILEY-VCH}

Copyright WILEY-VCH Verlag GmbH \& Co. KGaA, 69469 Weinheim, Germany, 2018.

Supporting Information

How Humidity and Light Exposure Change the Photophysics of Metal Halide Perovskite Solar Cells

Esma Ugur,* Erkki Alarousu, Jafar I. Khan, Aleš Vlk, Erkan Aydin, Michele De Bastiani, Ahmed H. Balawi, Sandra P. Gonzalez-Lopez, Martin Ledinský, Stefaan De Wolf, and Frédéric Laquai* 


\section{WILEY-VCH}

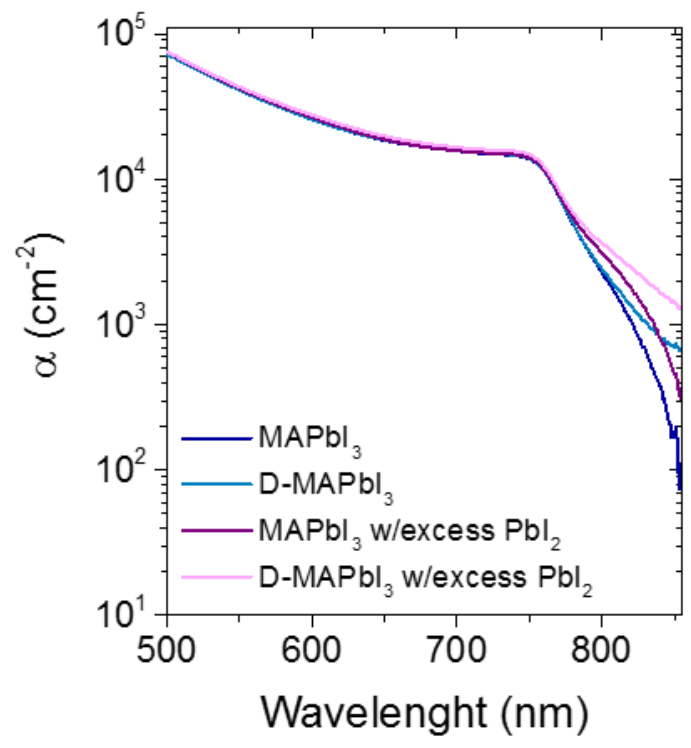

Figure S1. Absorption coefficient of the perovskite films. 


\section{WILEY-VCH}

a

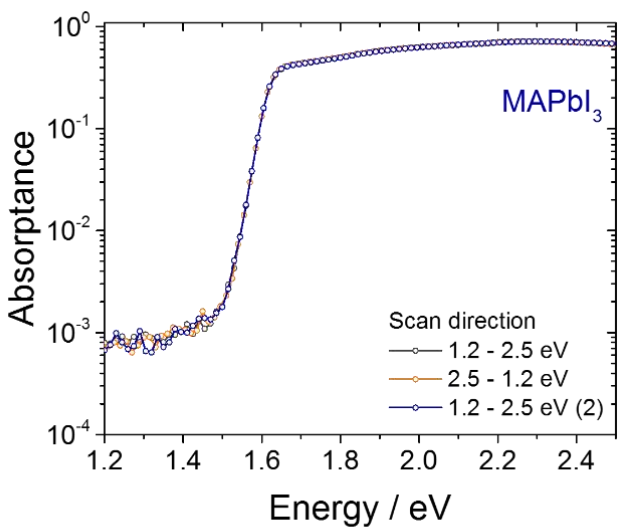

C

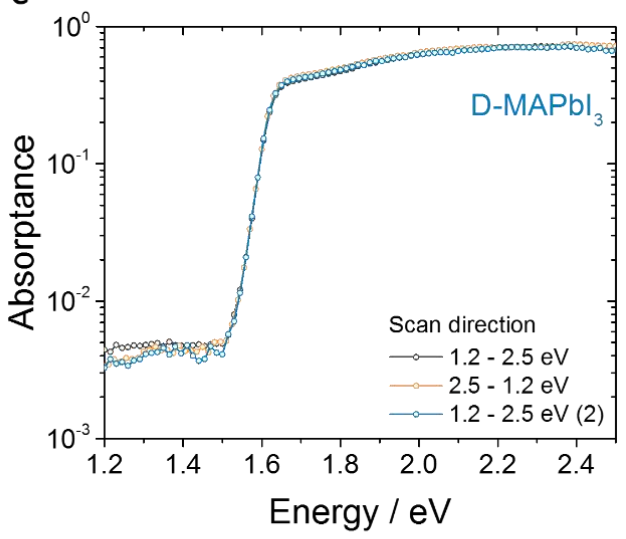

e

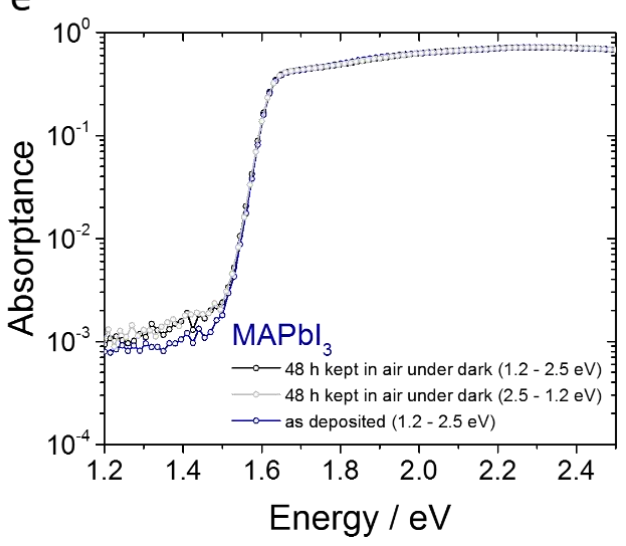

b

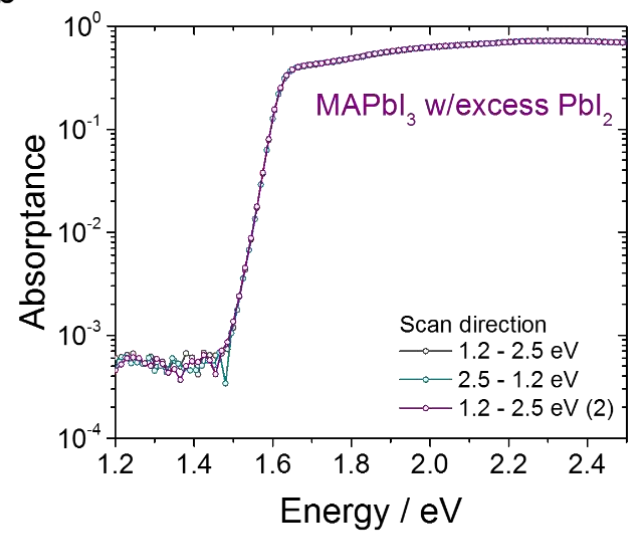

d

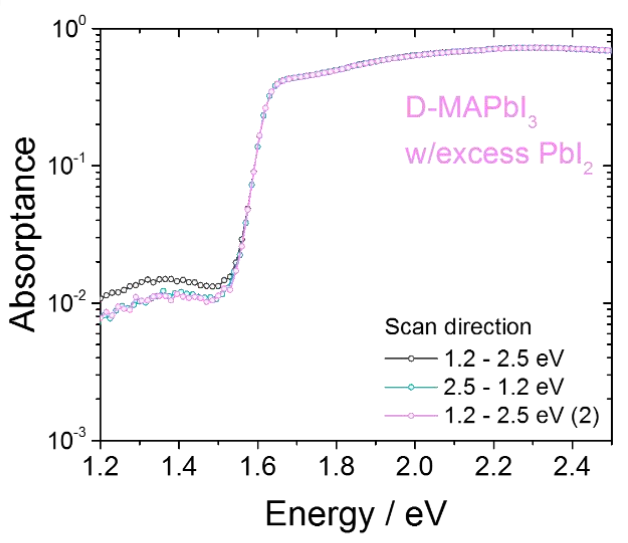

f

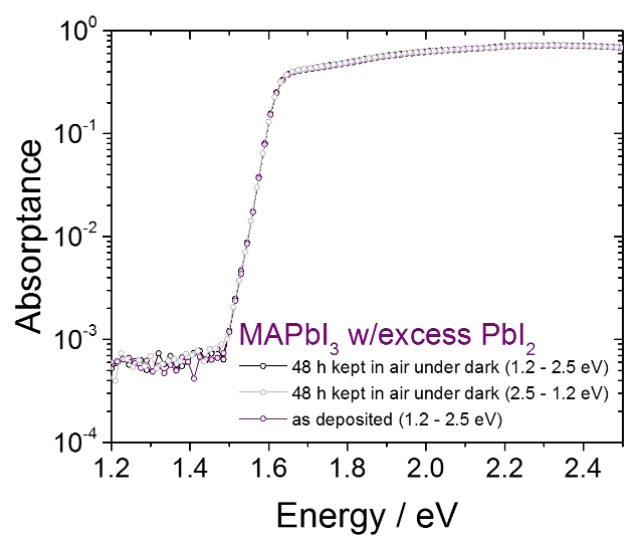

Figure S2. PDS spectra of a) $\mathrm{MAPbI}_{3}$, b) $\mathrm{MAPbI}_{3}$ with excess $\mathrm{PbI}_{2}$, c) D-MAPbI ${ }_{3}$, and d) DMAPbI ${ }_{3}$ with excess $\mathrm{PbI}_{2}$ perovskite films. e) and f) show the PDS spectra of $\mathrm{MAPbI}_{3}$ and $\mathrm{MAPbI}_{3}$ with excess $\mathrm{PbI}_{2}$ films stored in dark for 48 hours, respectively. PDS spectra of the films collected with different scan directions which are from low energy $(1.2 \mathrm{eV})$ to high energy $(2.5 \mathrm{eV})$ and vice versa. 


\section{WILEY-VCH}

a

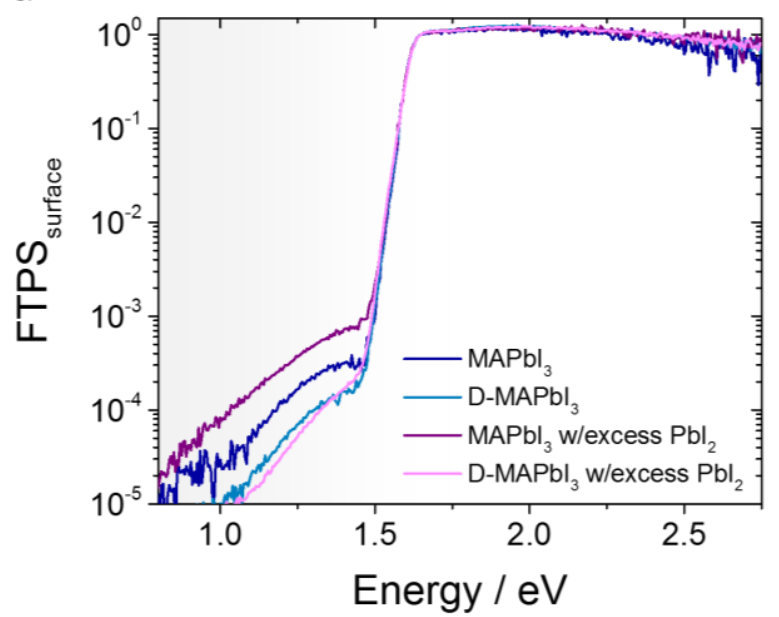

b

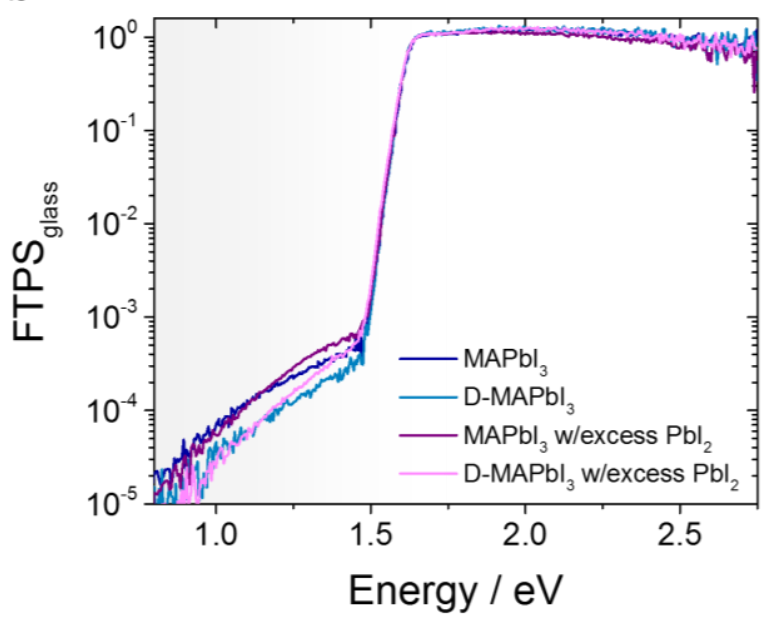

Figure S3. FTPS spectra of perovskite films excitation from a) the surface of the perovskite and, b) the glass substrate side. Shaded area in the spectrum shows the sub-bandgap region of the perovskite samples. 


\section{WILEY-VCH}

a

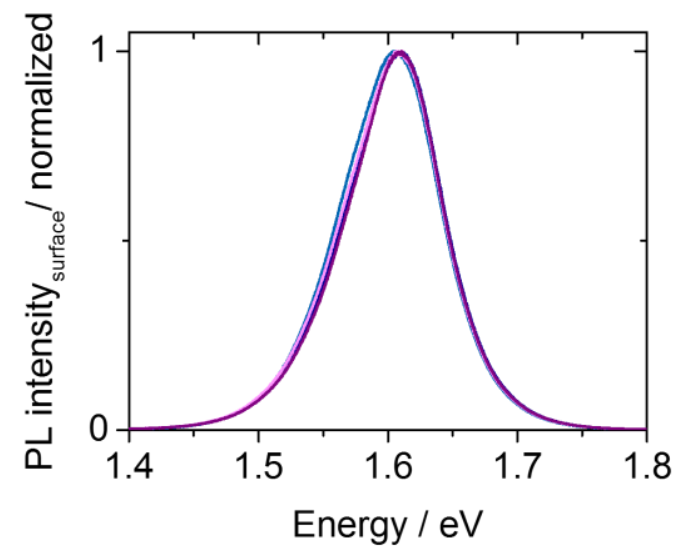

C
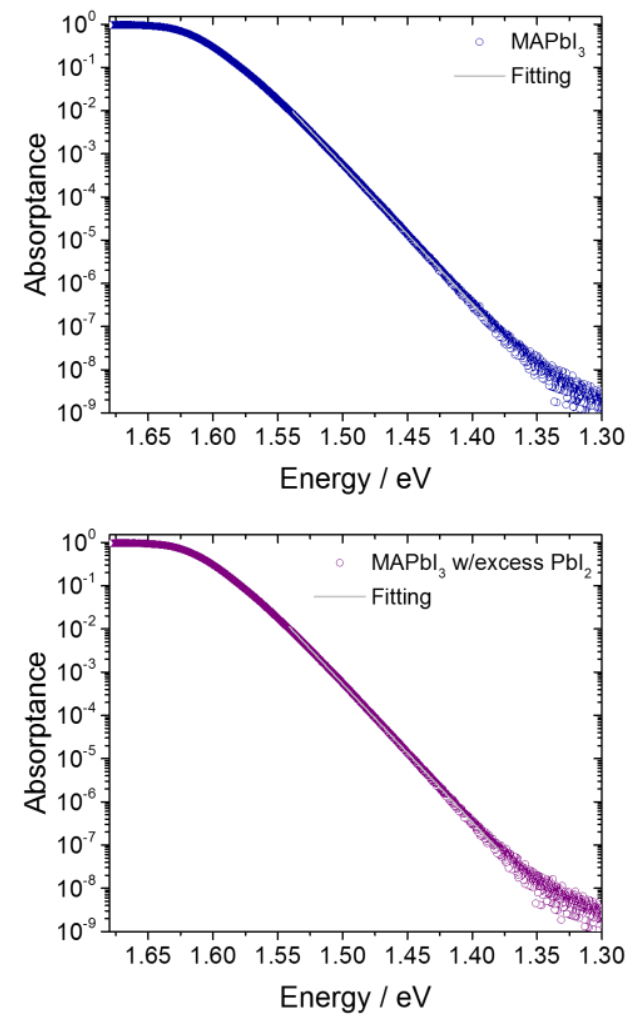

b

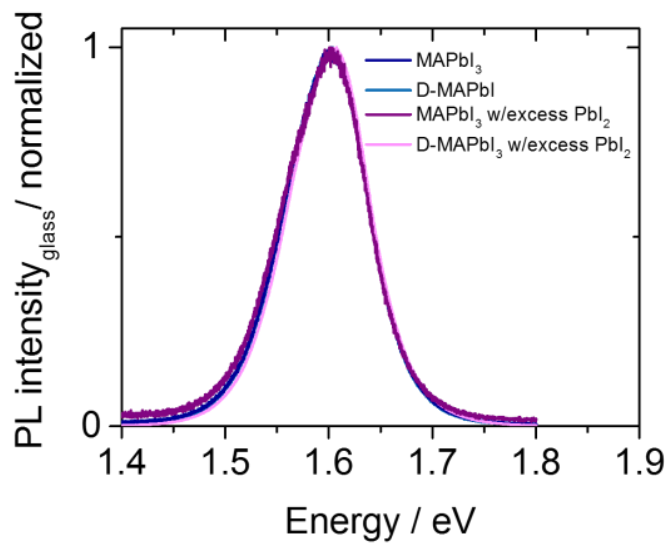

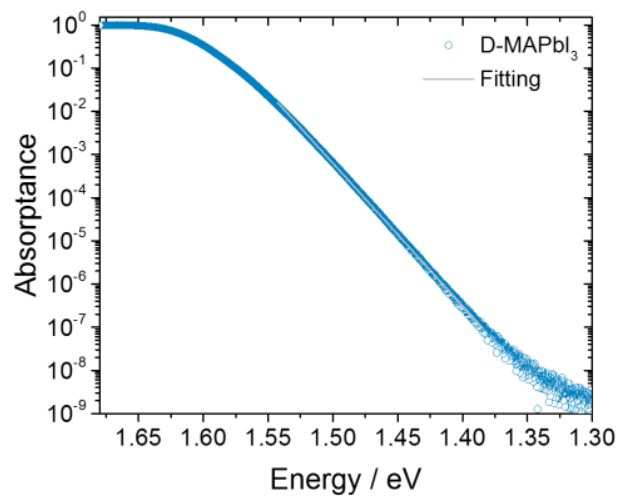

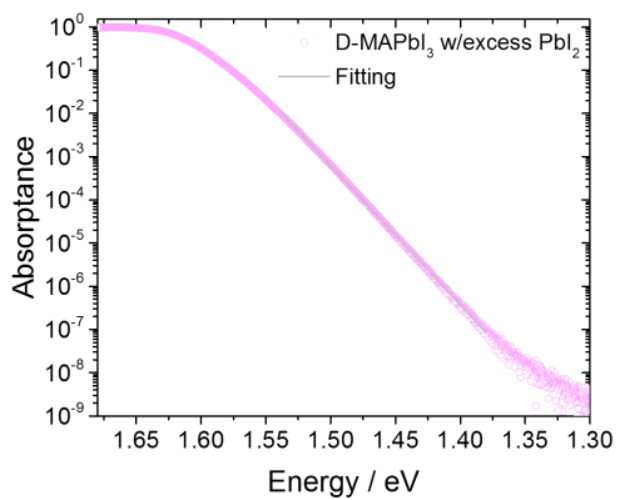

Figure S4. PL spectra of perovskite films excitation from a) the surface of the perovskite and, b) the glass substrate side. c) shows the absorptance spectra of the films extracted from PL spectra using reciprocity relation. 


\section{WILEY-VCH}
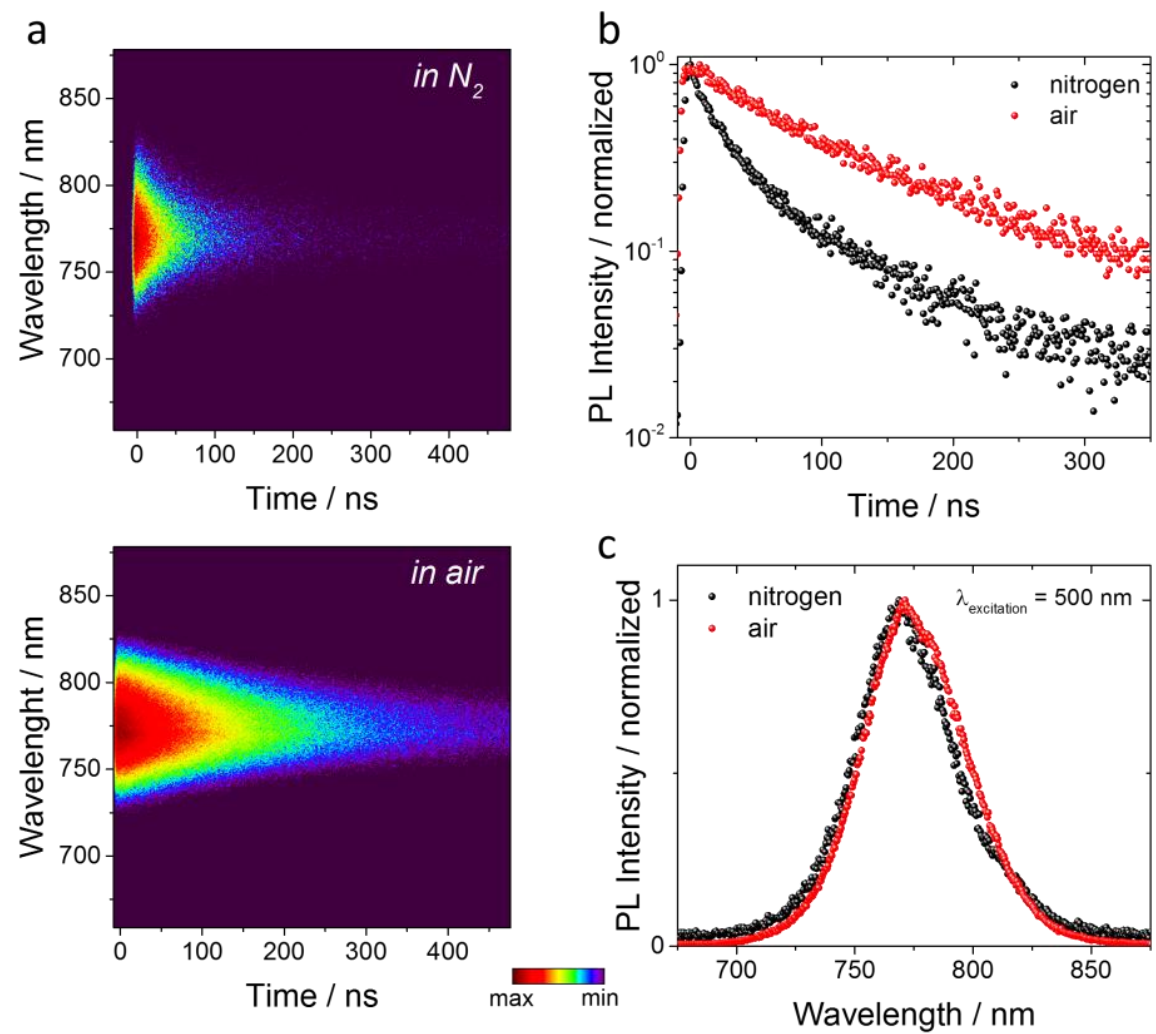

Figure S5. a) 2D pseudo color TR-PL plots of $\mathrm{MAPbI}_{3}$ perovskite films measured in nitrogen and air, b) TR-PL kinetics, and c) normalized PL spectra of perovskite samples extracted from 2D plots. Samples were excited at $500 \mathrm{~nm}$ using fluence $2 \mathrm{~nJ} \mathrm{~cm}$. 


\section{WILEY-VCH}

a

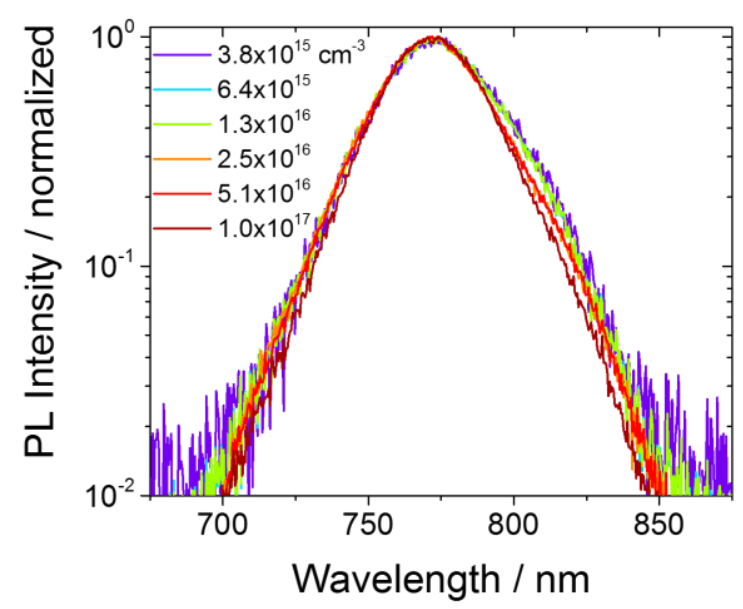

C

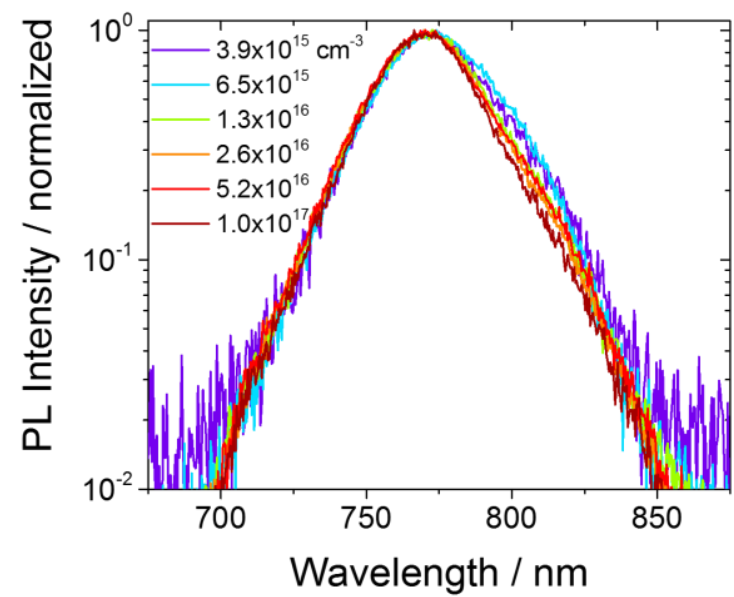

b

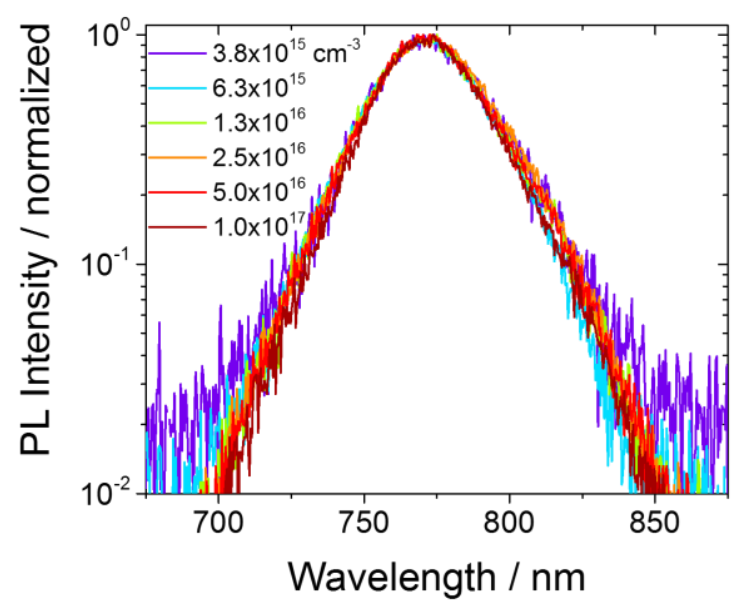

d

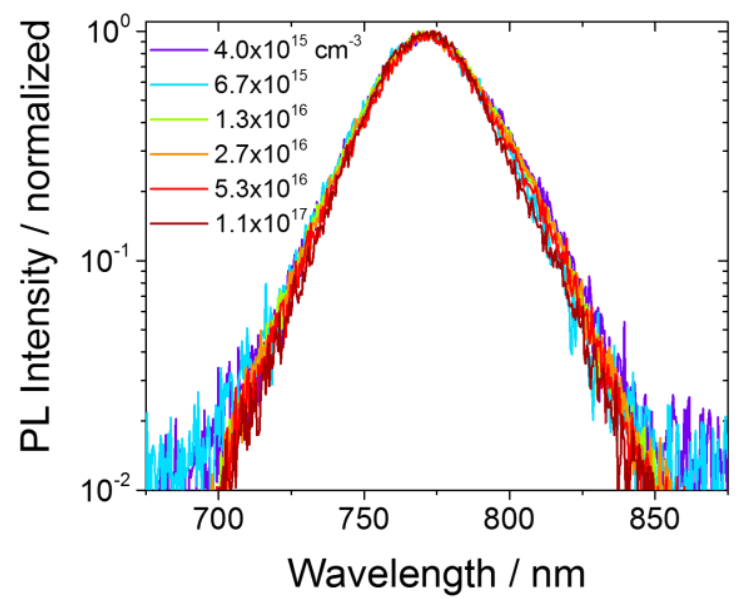

Figure S6. Normalized PL spectra of perovskite samples a) $\mathrm{MAPbI}_{3}$, b) D-MAPbI 3 , c) $\mathrm{MAPbI}_{3}$ with excess $\mathrm{PbI}_{2}$ and d) $\mathrm{D}-\mathrm{MAPbI}_{3}$ with excess $\mathrm{PbI}_{2}$. Samples were excited at $650 \mathrm{~nm}$ using fluences; 29, 49, 98, 194, 388 and $776 \mathrm{~nJ} \mathrm{~cm}^{-2}$, respectively. The excess carrier concentration $n_{0}$ is written in the graphs for respective excitation fluence. The repetition rate of the laser was $250 \mathrm{kHz}$. 


\section{WILEY-VCH}

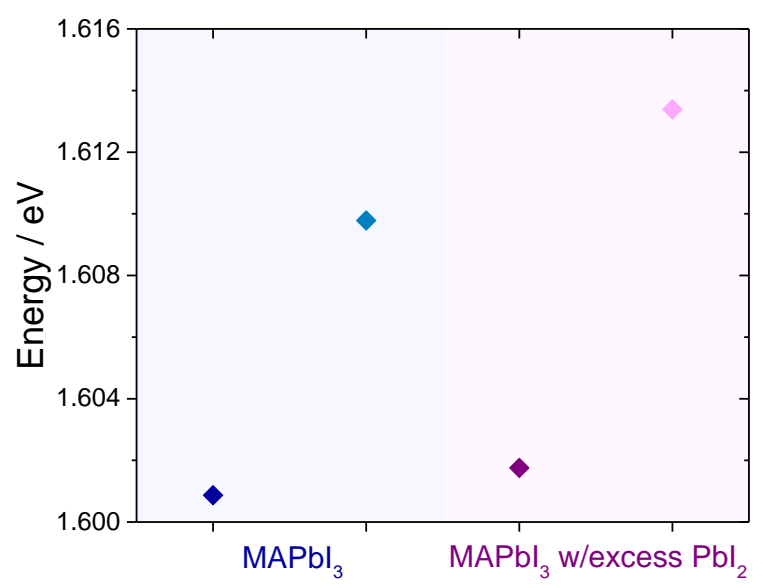

Figure S7. PL peak position of perovskite films in Figure $3 \mathrm{~b}$ (fluence $49 \mathrm{~nJ} \mathrm{~cm}{ }^{-2}$ ) which shows the blue shift for degraded films. 


\section{WILEY-VCH}

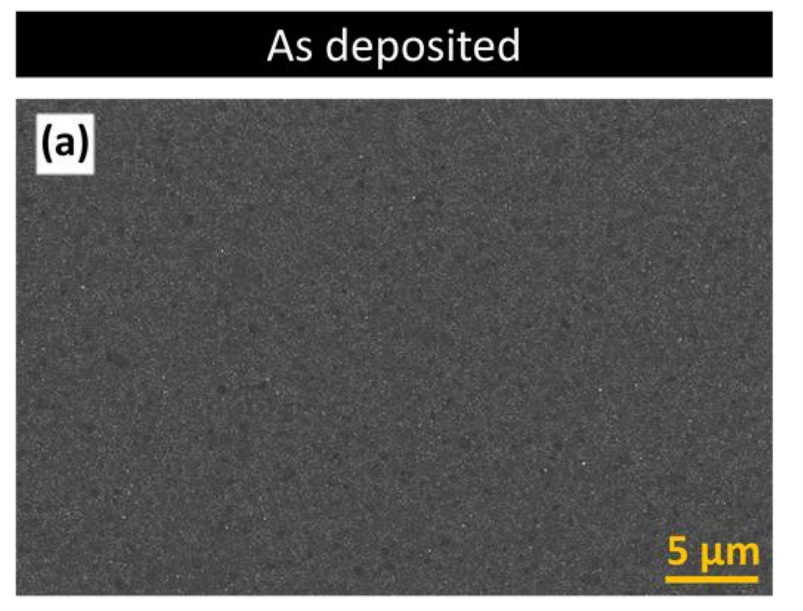

\section{1 sun illumination + humid air}
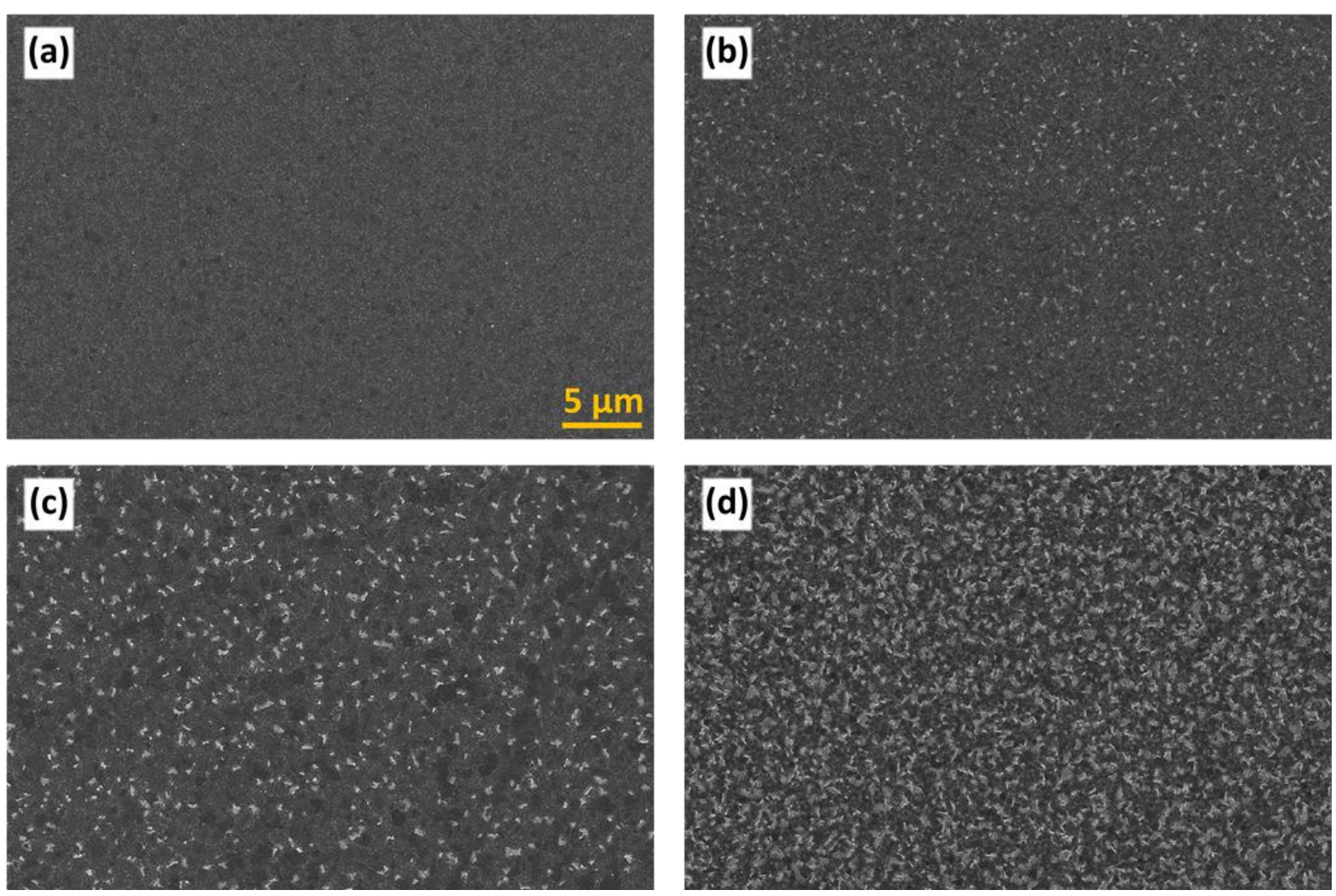

Figure S8. SEM micrographs of the related perovskite films (Scale bar: $5 \mu \mathrm{m}$ ). 


\section{WILEY-VCH}

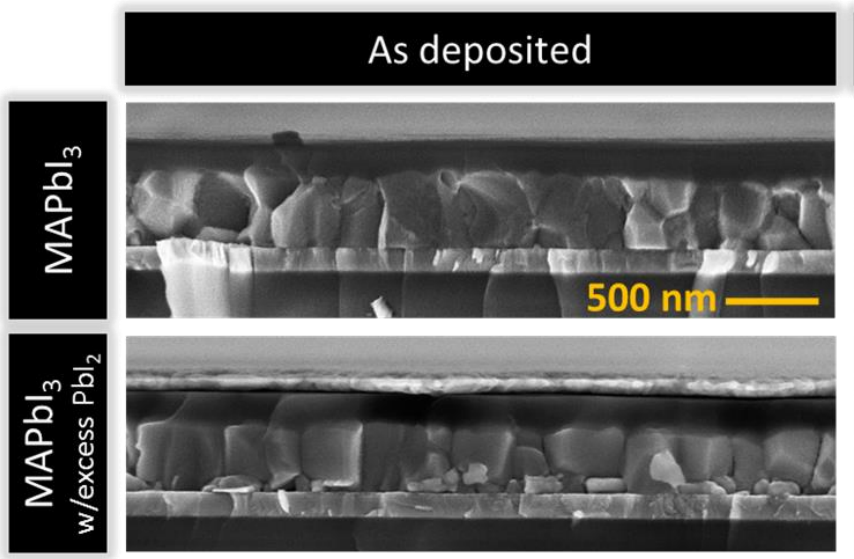

Exposed to humid air under illumination

Figure S9. Cross-sectional SEM images of related $n-i-p$ perovskite photovoltaic devices with device architecture $\mathrm{ITO} / \mathrm{SnO}_{2} / \mathrm{C} 60-\mathrm{SAM} /$ perovskite/spiro-OMeTAD/Au (Scale bar: $500 \mathrm{~nm}$ ). 


\section{WILEY-VCH}
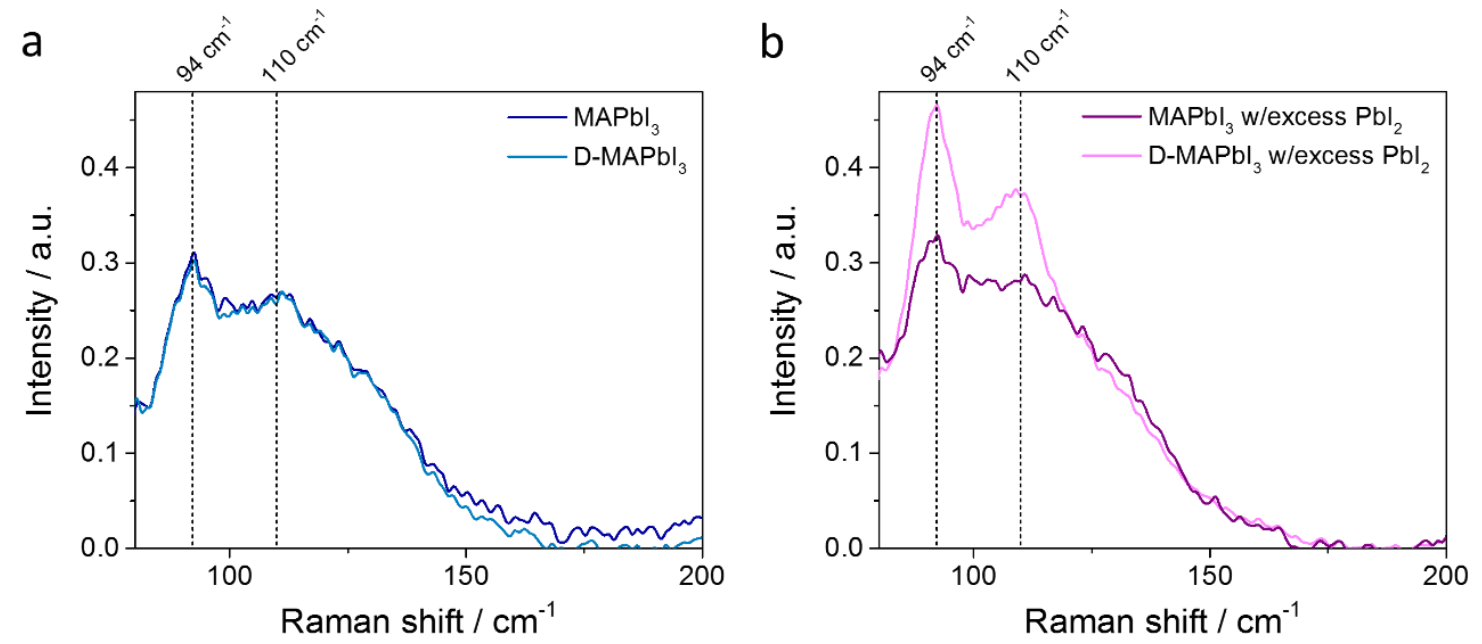

Figure S10. Raman spectra of a) $\mathrm{MAPbI}_{3}$ and b) $\mathrm{MAPbI}_{3}$ with excess $\mathrm{PbI}_{2}$ samples as deposited and after exposure to humid air under illumination. All spectra are normalized, following linear background subtraction, measured with a 1064 nm Raman laser. 


\section{WILEY-VCH}

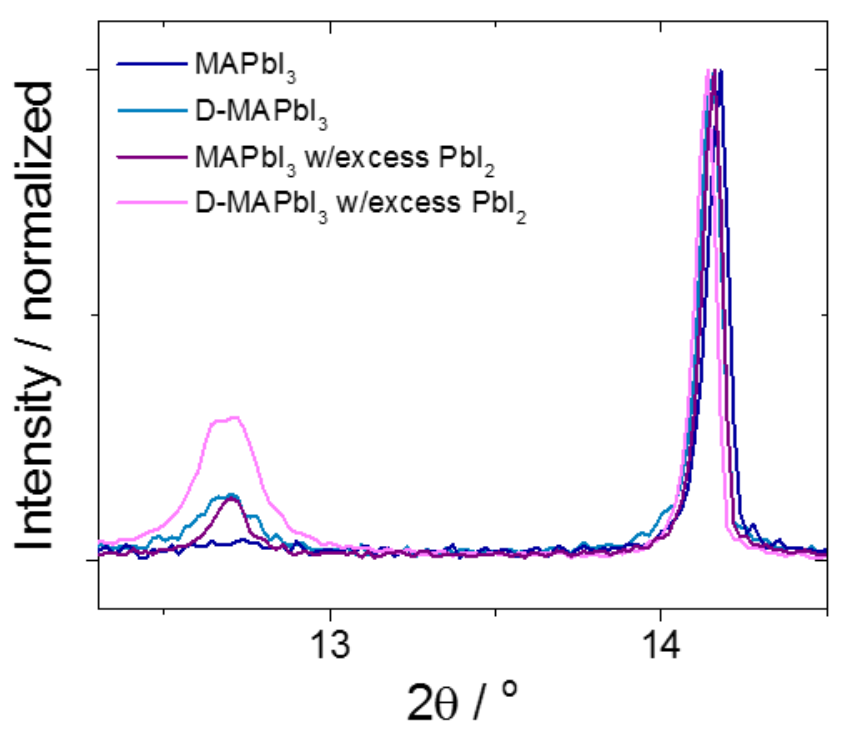

Figure S11. XRD pattern of perovskite samples at small $2 \theta$ angles as deposited and after exposure to humid air under illumination. The spectra are normalized, following linear background subtraction. 


\section{WILEY-VCH}

a

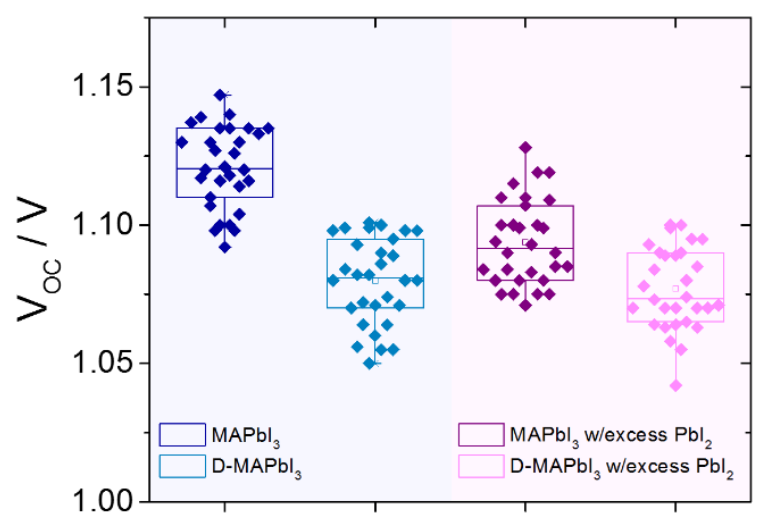

C

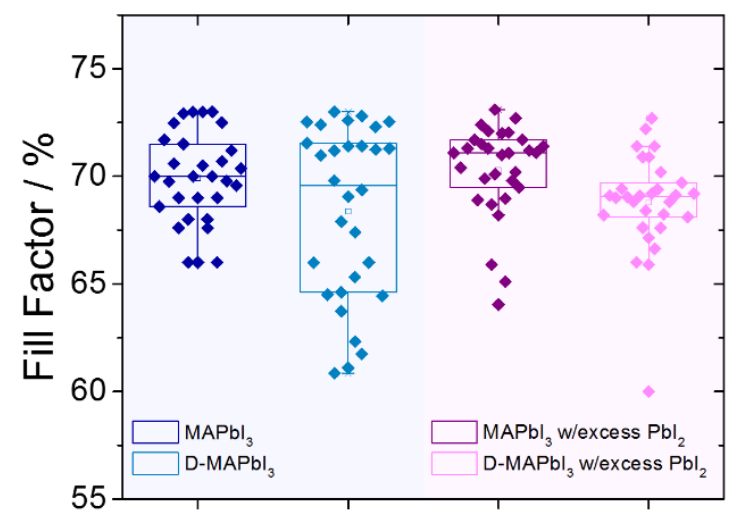

b

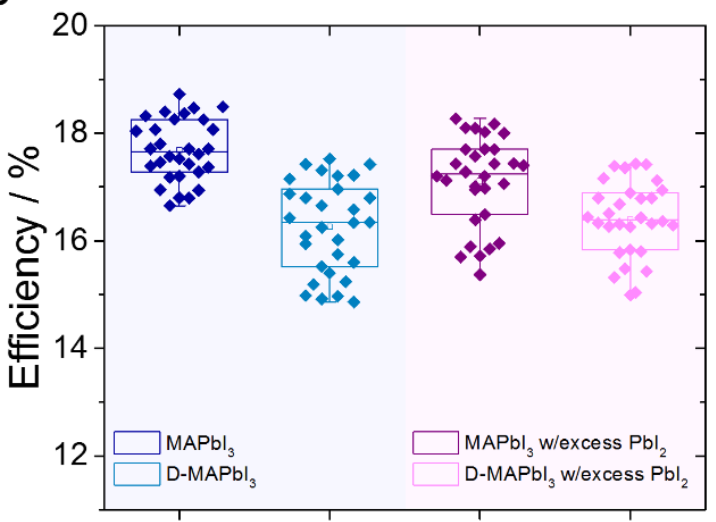

d

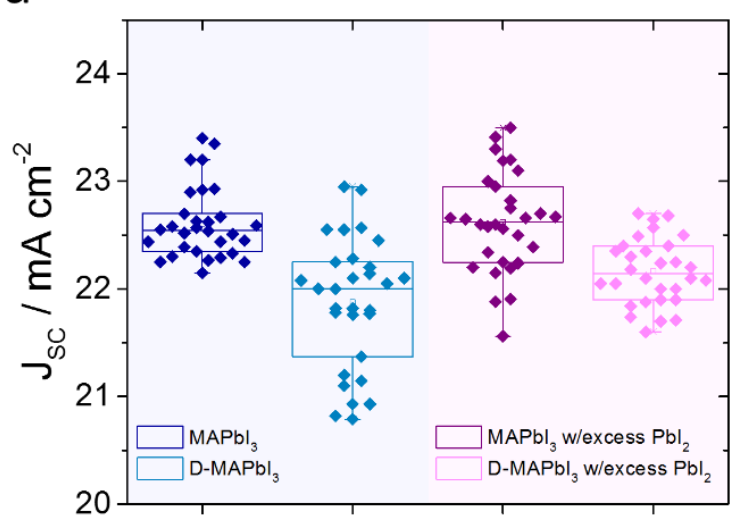

Figure S12. Histogram of a) $V_{O C}$, b) PCE, c) FF and d) $J_{S C}$ values for the $\mathrm{MAPbI}_{3}, \mathrm{D}_{-\mathrm{MAPbI}}$, MAPbI 3 with excess $\mathrm{PbI}_{2}$ and $\mathrm{D}-\mathrm{MAPbI}_{3}$ with excess $\mathrm{PbI}_{2}$ devices based on reverse $J-V$ sweeps $\left(\mathrm{V}_{\mathrm{OC}} \rightarrow \mathrm{J}_{\mathrm{SC}}\right)$. Statistics obtained from a total of 30 devices for each condition. 


\section{WILEY-VCH}

Table S1. Figures of Merit of $\mathrm{MAPbI}_{3}$ perovskite solar cells before and after exposure to humid air under illumination. ${ }^{*}$

\begin{tabular}{|c|c|c|c|c|}
\hline Sample & $\begin{array}{c}\mathrm{JSC}_{\mathrm{SC}} \\
\left(\mathrm{mA} \mathrm{cm}{ }^{-2}\right)\end{array}$ & $\begin{array}{l}V_{o c} \\
(\mathrm{mV})\end{array}$ & FF & $\begin{array}{c}\eta \\
(\%)\end{array}$ \\
\hline $\mathrm{MAPbl}_{3}$ & $22.61 \pm 0.34$ & $1121 \pm 15$ & $0.70 \pm 0.02$ & $17.69 \pm 0.57$ \\
\hline D-MAPbl 3 & $21.87 \pm 0.60$ & $1079 \pm 16$ & $0.68 \pm 0.04$ & $16.26 \pm 0.85$ \\
\hline $\mathrm{MAPbl}_{3} \mathrm{w} /$ excess $\mathrm{Pbl}_{2}$ & $22.62 \pm 0.47$ & $1094 \pm 16$ & $0.70 \pm 0.02$ & $17.11 \pm 0.83$ \\
\hline $\mathrm{D}-\mathrm{MAPbl}_{3} \mathrm{w} /$ excess $\mathrm{Pbl}_{2}$ & $22.17 \pm 0.31$ & $1077 \pm 15$ & $0.69 \pm 0.02$ & $16.40 \pm 0.70$ \\
\hline
\end{tabular}

* Shown here are average values of 30 devices based on reverse $J-V$ sweeps. 


\section{WILEY-VCH}

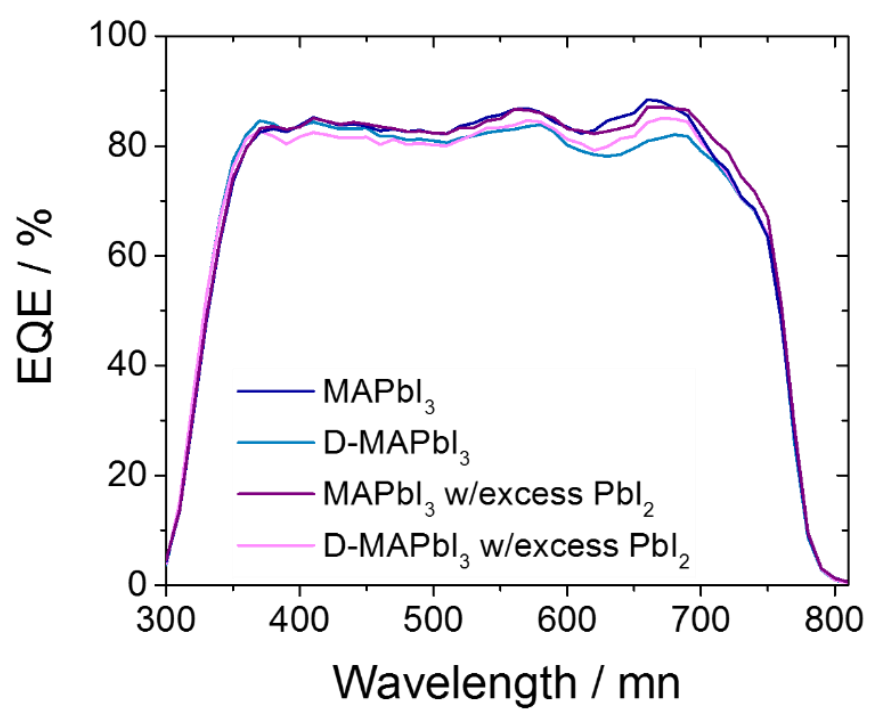

Figure S13. EQE spectra of the $\mathrm{MAPbI}_{3}, \mathrm{D}-\mathrm{MAPbI}_{3}, \mathrm{MAPbI}_{3}$ with excess $\mathrm{PbI}_{2}$ and $\mathrm{D}-\mathrm{MAPbI}$ with excess $\mathrm{PbI}_{2}$ devices. 

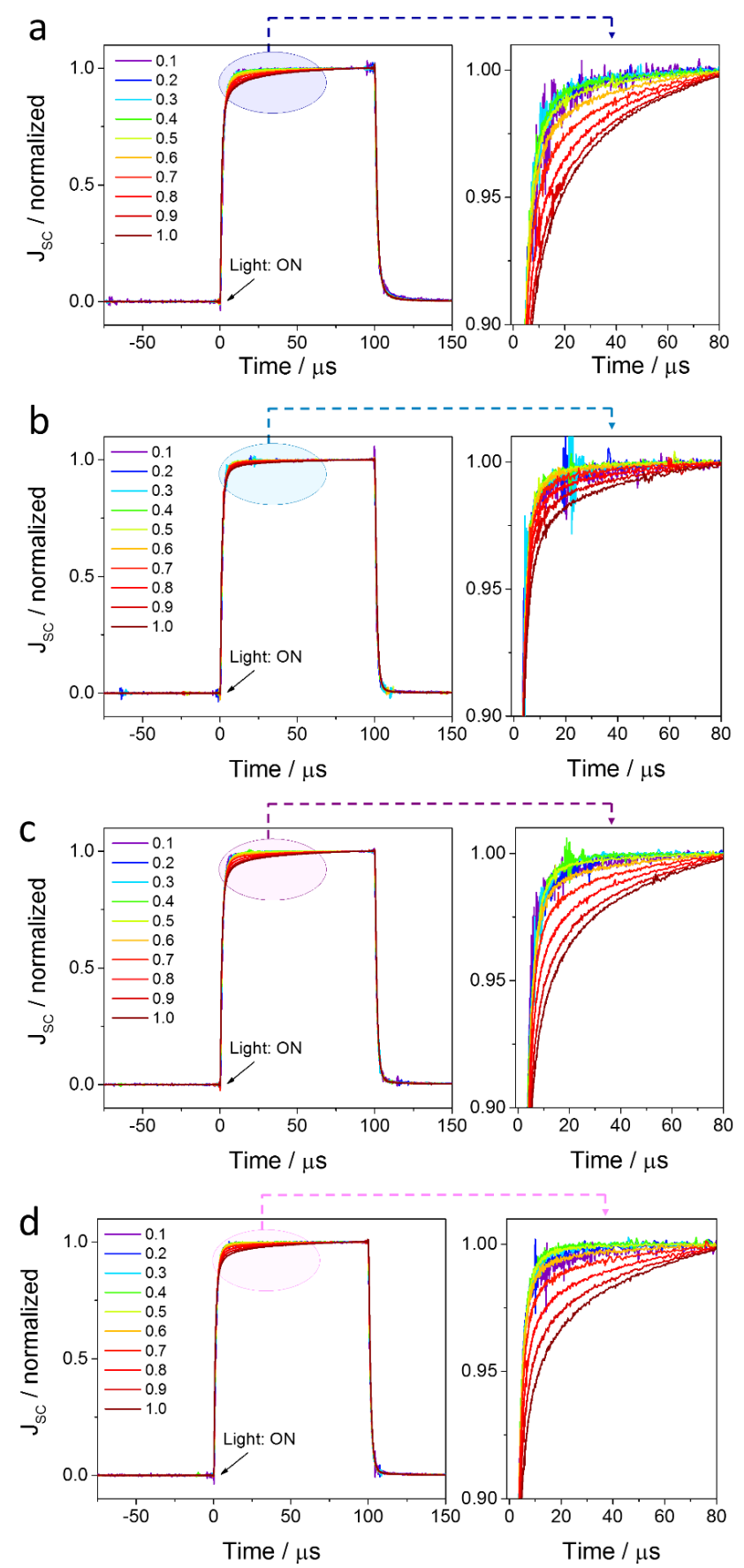

Figure S14. Transient photocurrent behavior of the a) $\mathrm{MAPbI}_{3}$, b) D-MAPbI 3, c) $\mathrm{MAPbI}_{3}$ with excess $\mathrm{PbI}_{2}$ and d) $\mathrm{D}-\mathrm{MAPbI}_{3}$ with excess $\mathrm{PbI}_{2}$ devices measured under a white light excitation with a $100 \mu$ s square pulse. Right panel of each graph shows detailed view of the rising behavior of the photocurrent. 